\title{
pH-Responsive Switchable Aggregation Phenomena of Xanthene Dyes Adsorbed on Tungsten(VI) Oxide Colloid Surface
}

Kenta ADACHI ${ }^{1 *}$, Kohei WATANABE ${ }^{1}$, and Suzuko YAMAZAKI ${ }^{1}$.

* To whom correspondence should be addressed. E-mail: k-adachi@yamaguchi-u.ac.jp

Notes: The authors declare no competing financial interest.

(1) Department of Environmental Science \& Engineering, Graduate School of Science \& Engineering, Yamaguchi University, Yamaguchi, 753-8512, Japan. Tel \& Fax: +81-83-933-5731. 


\begin{abstract}
The surface interactions between xanthene $(\mathrm{XN})$ dyes, including rhodamine $\mathrm{B}$, rhodamine 3B, rhodamine 19 , rhodamine $6 \mathrm{G}$, rhodamine 110 , and rhodamine 123 , and tungsten(VI) oxide $\left(\mathrm{WO}_{3}\right)$ colloid particles were investigated. These $\mathrm{XN}$ dyes were strongly adsorbed as monolayer onto the $\mathrm{WO}_{3}$ surface via the electrostatic interaction between their peripheral cationic amino-substituents and negatively surfacecharged $\mathrm{WO}_{3}$ colloid particles, and most of ones adsorbed eventually formed the stable $\pi$-stacked dimers. The geometry of dimers formed on the $\mathrm{WO}_{3}$ colloid surface is discussed on the molecular exciton theory framework. Cationic $\mathrm{XN}$ dyes formed the approximately ideal face-to-face $H$-dimers on the $\mathrm{WO}_{3}$ colloid surface, whereas zwitterionic ones had a higher tendency to form the oblique $J$-dimers. Additionally, we have experimentally demonstrated the possibility of $\mathrm{pH}$-induced switching between $H$-and $J$-aggregation modes of the $\mathrm{XN}$ dye's dimers formed on the $\mathrm{WO}_{3}$ colloid surface. The findings lead to a better understanding of organic dye's adsorption/aggregation behaviors on the metal oxide surface.
\end{abstract}

Keyword; Adsorption, Aggregation, Xanthene Dye, Tungsten Oxide, Switching. 


\section{INTRODUCTION}

Aggregation of organic dyes is widely found in nature, and plays an important role both in life sciences and material sciences. ${ }^{1-4}$ For instance, the photosynthetic process in the efficient light-harvesting system is related to the aggregation of the chlorophylls which are embedded in the well-organized thylakoid membranes of chloroplasts in plants ${ }^{5}$, and photodynamic therapies rely also on the dye's aggregation. ${ }^{6}$ Thus, the functions of the materials are not only determined by the individual molecules, but also by their aggregation states. The aggregation is easily observed in aqueous solution due to the development of shortrange non-covalent forces, such as $\pi$ - $\pi$ stacking and/or van der Waals interactions, among the organic dyes. ${ }^{7}$ Generally, the dye molecules can form two kinds of aggregate geometries, namely, $H$ - and $J$-aggregates, which are characterized by a blue-shifted and intense narrow red-shifted absorption compared to the monomer band, respectively. ${ }^{8}$ It is well-known that the aggregation behavior and geometry of organic dyes could be affected by many factors such as temperature, $\mathrm{pH}$, ionic strength, the concentration of the dyes, and the additive in the solution. ${ }^{9-11}$ Recently, external stimuli-responsive aggregations of dye molecules have been intensively studied in micelles, vesicles, liquid crystalline phases, microemulsions, polymer gels, aerosols, polymer-polymer and polymer-surfactant complexes with the aim of creating the forward-looking technologies for the solid-state dye lasers, chemical sensors, optical storage devices, light energy conversions systems, drug delivery, and photodynamic therapy. ${ }^{12,13}$ However, simple, instantaneous, and reversible control of the dye's aggregation still remains a challenging task for versatile and practical applications.

There has been considerable research interest focused on the study of the adsorption, aggregation, and photo-physicochemical properties of organic dyes on the surface of inorganic materials, because the interaction of dye molecules with metallic matters leads to a different photophysics and photochemistry than that found in homogeneous phases. ${ }^{14,15}$ Especially, in the field of dye-sensitized solar cells, organic dye monolayer adsorbed chemically on metal oxide semiconductors have been intensively investigated. ${ }^{16,17}$ The concept of exploiting energy/electron transfer between organic dyes and inorganic semiconductor materials 
to create nanoscale photofunctional interfaces has already been demonstrated, in which the dye's adsorptionaggregation geometry on the semiconductor surface is expected to be one of the key factors. ${ }^{18,19}$ Thus, tailoring photoelectro-chemical properties of the organic-inorganic hybrid nanocomposites would be achieved by assembling well-defined and controlled layers of organic dye molecules on the two-dimensional surface of inorganic semiconductor nanoparticles. In our previous studies, the adsorption/aggregation behaviors of cationic porphyrin and phenothiazine dyes on the inorganic semiconductor surface were favored by controlling the ionic strength in the aqueous solution and by substituent(s) introduction and modification in dye molecule, ${ }^{20,21}$ revealing that given adsorption/aggregation characteristics resulted from a complicated balance of various non-covalent interactions $(\pi-\pi$ stacking, van der Waals, steric-hindrance, and/or electrostatic attractive/repulsive interactions).

Being inspired by this concept, we extended the kind of strategy such as that in the present study by investigating the stimuli-responsive aggregation behaviors of various xanthene (XN) dyes adsorbed on the tungsten(VI) oxide $\left(\mathrm{WO}_{3}\right)$ colloid surface in aqueous solution by means of UV-Vis absorption measurements. $\mathrm{XN}$ dyes are frequently used as labeling agents in fluorescent protein measurements, sensitizers in solar energy conversion, and intercalating agents in cancer photodynamic therapy, as well as for application in tunable dye lasers due to their high quantum yield. ${ }^{22}$ Moreover, $\mathrm{XN}$ dyes tend to self-assemble into highlyordered aggregates, and therefore they are of much attention in relation to the creation of novel supramolecular architectures. ${ }^{22,23}$ As shown in Scheme 1, rhodamine B (RhB), rhodamine 3B (Rh3B), rhodamine 19 (Rh19), rhodamine 6G (Rh6G), rhodamine 110 (Rh110), and rhodamine 123 (Rh123) were selected to explore the effects of substituent(s) on the adsorption/aggregation behaviors in the $\mathrm{XN} / \mathrm{WO}_{3}$ aqueous system. On the other hand, $\mathrm{WO}_{3}$ is a wide gap n-type semiconductor with band gap of ca. 2.6 to 3.0 $\mathrm{eV}^{24,25}$ and one of the interesting materials for optoelectronic applications. From optical application point of view, $\mathrm{WO}_{3}$ is considered as chromogenic material and is potentially useful in the fabrication and development of electrochromic and photochromic devices. ${ }^{26}$ In addition, nanoscaled $\mathrm{WO}_{3}$ particles exhibit 
gas sensing properties and find application in sensor device technology where the controlled size, crystal structure, surface morphology, and electronic band structure of $\mathrm{WO}_{3}$ particles are believed to play a significant role. ${ }^{27}$ More recently, it has been demonstrated that photochromic $\mathrm{WO}_{3}$ nanocolloid particles exhibit colorimetric sensing properties for $\alpha$-amino acid compounds in aqueous solutions, which will have numerous applications in continuous in vivo monitoring. ${ }^{28}$ In the $\mathrm{XN} / \mathrm{WO}_{3}$ aqueous system, we have found that through using the $\mathrm{XN}$ dyes containing carboxyl group on the pendant phenyl ring $(\mathrm{RhB}, \mathrm{Rh} 19$, and Rh110), the $H$ - and $J$-aggregation on the $\mathrm{WO}_{3}$ colloid surface could be regulated in a more versatile manner and various interesting surface nanoarchitecture geometries could be formed. Particularly, the proton dissociation of the carboxyl group could be overriding factor. Furthermore, the aforementioned $\mathrm{XN} / \mathrm{WO}_{3}$ aqueous systems showed an interesting reversible conversion between different aggregates depending upon $\mathrm{pH}$ value. The switch between the $H$-and $J$-aggregation modes is vital in regulating the properties of the $\mathrm{XN}$ dye's aggregates. Our novel results described here clearly show the importance of the balanced non-covalent interactions for the construction of highly ordered and reversible dye's aggregates formed on the metal oxide surface with unique optical properties as required for various kinds of optoelectronic application. 


\section{EXPERIMENTAL}

Unless specified in particular, all measurements in this study were carried out in a thermostated room at $25 \pm 2^{\circ} \mathrm{C}$.

\subsection{Materials}

Sodium tungstate(VI) dihydrate $\left(\mathrm{Na}_{2} \mathrm{WO}_{4} \cdot 2 \mathrm{H}_{2} \mathrm{O}\right)$ and dialytic membranes with 3500 molecular weight cut-off were purchased from Wako Pure Chemical (Osaka, Japan) and Spectrum Laboratories (CA, USA), respectively. Six xanthene $(\mathrm{XN})$ dyes, containing rhodamine $\mathrm{B}(\mathrm{RhB})$ rhodamine $3 \mathrm{~B}(\mathrm{Rh} 3 \mathrm{~B})$, rhodamine 19 (Rh19), rhodamine 6G (Rh6G), rhodamine 110 (Rh110), and rhodamine 123 (Rh123), were obtained from Sigma-Aldrich (Milwaukee, USA) and recrystallized from a chloroform-methanol. The water, with a specific resistivity of $18.2 \mathrm{M} \Omega \mathrm{cm}$, was obtained using a Milli-Q water purification system (Millipore, USA). All other chemicals were of reagent grade from Wako Pure Chemical (Osaka, Japan), Tokyo Kasei Kogyo (Tokyo, Japan) or Nacalai Tesque Inc. (Kyoto, Japan), and were used as received without further purification.

\subsection{Preparation of $\mathrm{WO}_{3}$ colloid aqueous solution.}

The preparation procedure of $\mathrm{WO}_{3}$ colloid aqueous solution is based on the techniques reported by Zou et al. ${ }^{29}$ Conc. $\mathrm{HCl}(9.7 \mathrm{~mL}, 0.7 \mathrm{M})$ was added drop by drop to a $\mathrm{Na}_{2} \mathrm{WO}_{4}$ solution $(90 \mathrm{~mL}, 0.027 \mathrm{M})$ under magnetic stirring. A transparent aqueous colloid solution was obtained, which was then closed in a dialytic membrane pipe and dialyzed in a $1000 \mathrm{~mL}$ beaker containing Milli-Q water for a period of 8 hours. The deionized water was periodically replaced until $\mathrm{Cl}$ ions could not be detected by an ion-chromatograph (PIA-1000, Shimadzu, Japan) equipped with an anion-exchange column (Shim-pack IC-AC, Shimadzu, Japan). The concentration of tungsten component in the $\mathrm{WO}_{3}$ colloid aqueous solution was determined by inductively coupled plasma-atomic emission spectrometry (Liberty Series II, Varian, USA). The as-prepared 
$\mathrm{WO}_{3}$ colloid solutions were stable for at least one month at room temperature without any stabilizing agents, yielding excellent processability, and refrigerated at $4^{\circ} \mathrm{C}$ until used in the experiments. However, under strongly acidic conditions ( $\mathrm{pH}$ region below its isoelectric point), the $\mathrm{WO}_{3}$ colloid solution had poor stability and resulted in precipitation, probably due to the coagulation of the $\mathrm{WO}_{3}$ particles.

\subsection{Adsorption-Aggregation Experiments of $\mathrm{XN}$ dyes on the $\mathrm{WO}_{3}$ Colloid Surface.}

A typical experiment would consist of first mixing the $\mathrm{XN}$ dyes aqueous solution, water, sodium sulfate (ionic strength adjustment), and hydrochloric acid or sodium hydrate. Then, the $\mathrm{WO}_{3}$ colloid aqueous solution would be added and stirred for $10 \mathrm{~min}$ at room temperature. It was preliminarily established that this time is sufficient for the establishment of adsorption-aggregation equilibrium. The $\mathrm{pH}$ values of the $\mathrm{XN} / \mathrm{WO}_{3}$ aqueous solution were periodically checked with an F-14 pH meter (Horiba, Japan) equipped with a 636610D glass electrode (Horiba, Japan). The $\mathrm{XN} / \mathrm{WO}_{3}$ aqueous solution was injected into a single compartment cell $(0.1$ or $1.0 \mathrm{~cm}$ path-length $)$ with two quartz window. Afterward, static UV-visible spectra of the $\mathrm{XN} / \mathrm{WO}_{3}$ aqueous solution were obtained on a UV-1800 spectrometer (Shimadzu, Japan).

\subsection{Other Apparatus.}

Nitrogen adsorption-desorption isotherm was performed at $-195.8^{\circ} \mathrm{C}$ on a TriStar II 3020 analyzer (Micromeritics, USA). Dried $\mathrm{WO}_{3}$ colloid samples $(c a .0 .5 \mathrm{~g})$ were prepared by evaporating water from the $\mathrm{WO}_{3}$ colloid aqueous solution, and then outgassed with helium for 2 hours at $200^{\circ} \mathrm{C}$ in an outgassing station of the adsorption apparatus before the adsorption measurements. The surface areas are measured using the Brunauer-Emmett-Teller (BET) method. ${ }^{30}$ By using the Barrett-Joyner-Halenda (BJH) model, ${ }^{31}$ the pore size distributions were derived from the adsorption branches of isotherms. As previously reported, ${ }^{32}$ the specific surface area is $11.8 \mathrm{~m}^{2} \mathrm{~g}^{-1}$ and the pore size is about $50 \mathrm{~nm}$. 
The TEM images of $\mathrm{WO}_{3}$ colloids before and after the addition of $\mathrm{XN}$ dyes were measured with a JEM-2000EX II instrument (JEOL, Japan). The TEM samples were prepared by dropping the $\mathrm{WO}_{3}$ colloid sample solution onto a copper grid covered with a carbon film and dried in air. The final XN dyes concentration in the $\mathrm{WO}_{3}$ colloid aqueous sample solution was $5.0 \times 10^{-5} \mathrm{M}$. The particle size distributions of $\mathrm{WO}_{3}$ colloids were evaluated by averaging the sizes of 100 particles directly from the TEM images and an optical particle-size analyzer (SALD-7100, Shimadzu, Japan). 


\section{RESULTS AND DISCUSSION}

\subsection{Self-Aggregation of XN Dyes in Water.}

Xanthene $(\mathrm{XN})$ dyes containing the carboxyl group $(-\mathrm{COOH})$ on the bottom phenyl ring, such as $\mathrm{RhB}, \mathrm{Rh} 19$, and Rh110, must give rise to cation/zwitterion equilibrium generated by proton dissociation. As shown in Figure S3, UV-visible spectra of RhB, Rh19, and Rh110 aqueous solutions changed with the pH in a range between 1 and 6 . From these spectral changes, the acid dissociation constants $\left(\mathrm{p} K_{\mathrm{a}}\right)$ of $\mathrm{RhB}, \mathrm{Rh} 19$, and Rh110 were $3.31,3.28$, and 3.30, respectively, in coincidence with values reported in the literatures (ca. 3.2-3.3) $3^{33-35}$. Common $\mathrm{XN}$ dyes have a strong tendency to form dimers at high concentration, via $\pi-\pi$ interaction due to their extended aromatic surface. ${ }^{36}$ Specifically, the absorption spectra of XN dyes are of interest in connection with their monomer-dimer equilibrium and dimer geometries. ${ }^{37,38}$ To confirm the selfdimerization in water, the absorption spectra were measured in the concentration from $1.0 \times 10^{-6}$ to $2.0 \times 10^{-3} \mathrm{M}$ at $\mathrm{pH} 2$ and 6. For example, as can be seen in Figure 1(a), with an increasing in $\mathrm{RhB}$ concentration at $\mathrm{pH} 2$, the strong monomer absorption band at $558 \mathrm{~nm}$ gradually decreased and isosbestically blue-shifted, and eventually the spectra showed discernible shoulder at around $520 \mathrm{~nm}$. The isosbestic points were clearly found in this wavelength region, showing that the spectral changes were governed by an initial and a final species with no side reactions. Although there were some differences in detail, similar spectral changes were observed for other XN dyes, regardless of $\mathrm{pH}$ values (for want of space, Rh123, Rh3B, and Rh6G spectra at pH 2 were not shown). In these all cases, the substantial broadening, concomitant decrease in intensity, and blue-shift of monomer band are indicative of the presence of $H$-type (face-to-face fashion) dimer. ${ }^{8}$ To obtain the dimerization constant $\left(K_{\mathrm{d}}\right)$ of $\mathrm{XN}$ dyes in acidic and neutral water, the maximum molar extinction coefficient was plotted as a function of total concentration, on the basis of the following equation;

$$
\begin{aligned}
& 2 \mathrm{XN} \stackrel{K_{\mathrm{d}}}{=}(\mathrm{XN})_{2} \\
& K_{\mathrm{d}}=\frac{\left[(\mathrm{XN})_{2}\right]}{[\mathrm{XN}]^{2}}=\frac{1-x}{2 x^{2} C} .
\end{aligned}
$$


where $\left[(\mathrm{XN})_{2}\right]$ and $[\mathrm{XN}]$ are the concentration of $\mathrm{XN}$ dye dimer and monomer in the aqueous solution, respectively, and $x$ is the mole fraction of monomer at overall $\mathrm{XN}$ dye's concentration $C$. The appearance molar extinction coefficient, $\varepsilon$, at a wavelength used in the data acquisition is

$$
\varepsilon=\varepsilon_{\mathrm{m}} x+\varepsilon_{\mathrm{d}}(1-x)
$$

where $\varepsilon_{\mathrm{m}}$ and $\varepsilon_{\mathrm{d}}$ are the molar extinction coefficients of the monomer and dimer, respectively. Because the absorbance of the diluted solutions $\left(<1.0 \times 10^{-6} \mathrm{M}\right)$ gave the $\varepsilon_{\mathrm{m}}$ values, the $K_{\mathrm{d}}$ and $\varepsilon_{\mathrm{d}}$ values for XN dyes were calculated from the least-squares curve-fitting, as shown in inset of Figure 1. These values were listed in Table S1 (see Supporting Information), and in good agreement with earlier results reported by other workers. ${ }^{34,39,40}$ Under same $\mathrm{pH}$ condition, the $K_{\mathrm{d}}$ values are increased in the order of $\mathrm{Rh} 110<\mathrm{RhB}<\mathrm{Rh} 123$ $<\mathrm{Rh} 3 \mathrm{~B}<\mathrm{Rh} 19<\mathrm{Rh} 6 \mathrm{G}$. Moreover, it is noted that the $K_{\mathrm{d}}$ values of XN dyes with carboxyl group $(-\mathrm{COOH})$ on the bottom phenyl ring ( $\mathrm{RhB}, \mathrm{Rh} 19$, and $\mathrm{Rh} 110)$ are strongly dependent on $\mathrm{pH}$, though no significant $\mathrm{pH}$ dependence is observed for ones with carboxyl-ester group (-COOR) on the bottom phenyl ring (Rh3B, $\mathrm{Rh} 6 \mathrm{~B}$, and Rh123). From these results, it is revealed that the $K_{\mathrm{d}}$ values sensitively increase by the methyl substitution in the xanthene plane and/or the modification of peripheral amino groups with the ethyl groups. Also the proton dissociation of carboxyl group on the bottom phenyl ring affect the dimerization behavior in water. The findings clearly imply that the competition of the hydrophobic and electrostatic interaction between the $\mathrm{XN}$ dye molecules mainly plays an important role in the self-dimerization in water.

The pure monomer and dimer spectra were calculated from the ten concentration-dependent spectra using Eq. (1) and Eq. (2). Figure 2 shows the monomer and dimer spectra of six XN dyes. The pure dimer spectra of XN dyes mainly consist of two components which appear on the short- and long-wavelength side relative to the monomer band. The conformation of $\mathrm{XN}$ dye dimer formed in water will be discussed in section 3.4 . 


\subsection{Adsorption/Aggregation of $\mathrm{XN}$ Dyes on the $\mathrm{WO}_{3}$ Colloid Surface.}

The aggregation phenomena of $\mathrm{XN}$ dyes in the $\mathrm{WO}_{3}$ colloid aqueous solution were also clearly observed. The typical absorption changes of $\mathrm{XN}$ dyes in acidic $(\mathrm{pH} 2)$ and neutral water (pH 6) with an increasing concentration of the $\mathrm{WO}_{3}$ colloid from 0 to $1.0 \times 10^{-3} \mathrm{M}$ are shown in Figure 3 . In all $\mathrm{XN} / \mathrm{WO}_{3}$ aqueous systems, an addition of $\mathrm{WO}_{3}$ colloid aqueous solution into $\mathrm{XN}$ dyes aqueous solution led to significant spectroscopic changes. As shown in Fig. 3(c), (f), and (i), a drastic, gradual decrease in monomer absorption band of $\mathrm{XN}$ dyes with "carboxyl-ester group" on the bottom phenyl ring ( $\mathrm{Rh} 3 \mathrm{~B}$, Rh6G, and Rh123, respectively) was observed with a titration of the $\mathrm{WO}_{3}$ colloid solution, along with a blue-shift in maximum absorption to a shorter wavelength regardless of $\mathrm{pH}$ conditions. (Rh3B, Rh6G, and $\mathrm{Rh} 123$ spectra under $\mathrm{pH} 2$ were not shown here, because similar spectral changes were observed under $\mathrm{pH}$ 6.) Meanwhile, depending upon aqueous $\mathrm{pH}$ conditions, $\mathrm{XN}$ dyes with "carboxyl group" on the bottom phenyl ring (RhB, Rh19, and Rh110) have different results. With increasing $\mathrm{WO}_{3}$ colloid concentration, the monomer band for RhB, Rh19, and Rh110 decreased sharply and shifted to shorter wavelength at pH 2 (Fig. 3(a), (d) and (g), respectively), but shifted to longer wavelength at pH 6 (Fig. 3(b), (e) and (h), respectively). According to the molecular exciton model, the blue-shift is a sign of the $H$-aggregate formation (face-to-face fashion), whereas the red-shift is a sign of the $J$-aggregate formation (head-to-tail fashion). The contrasting spectral shifts indicate that $\mathrm{RhB}, \mathrm{Rh} 19$, and $\mathrm{Rh} 110$ in the neutral $\mathrm{WO}_{3}$ colloid aqueous solution are enforced to adopt the $J$ aggregation mode, whereas those in the acidic $\mathrm{WO}_{3}$ colloid aqueous solution enjoy the $H$-aggregation mode similar to the self-dimerization in water as described above section.

Although UV-visible adsorption spectra look different during a titration of $\mathrm{WO}_{3}$ colloid solution, in all $\mathrm{XN} / \mathrm{WO}_{3}$ aqueous systems, noteworthy are the isosbestic points observed: this leads to the conclusion that the initial and final species are in equilibrium. As can be seen from the above section, the dimerization of $\mathrm{XN}$ dyes in water is almost negligible under this dye concentration $\left(1.0 \times 10^{-6} \mathrm{M}\right)$. The well-known process on the metal oxide surface in aqueous solution is the surface charging due to interactions of $-\mathrm{OH}$ groups with 
the $\mathrm{H}^{+}$ions. Therefore, the $-\mathrm{OH}$ groups on the metal oxide surface exist as $-\mathrm{OH}_{2}^{+}$and $-\mathrm{O}^{-}$respectively when the $\mathrm{pH}$ is lower and higher than the isoelectric point, $\mathrm{p} I{ }^{41}$ Because the $\mathrm{p} I$ value of tungsten(VI) oxide is $0.2-$ $0.5,{ }^{42}$ the $\mathrm{WO}_{3}$ colloid surface is negatively charged under the $\mathrm{pH}$ conditions used in this study $(\mathrm{pH}=2 \sim 6)$. Therefore, these spectral changes of $\mathrm{XN}$ dyes with increasing $\mathrm{WO}_{3}$ concentrations were assigned to formation of aggregates on the $\mathrm{WO}_{3}$ colloid surface via the electrostatic adsorption of cationic $\mathrm{XN}$ dye onto negatively charged $\mathrm{WO}_{3}$ nanocolloids. Considering the equilibrium between the $\mathrm{XN}$ dye monomer and aggregate on the $\mathrm{WO}_{3}$ colloid surface, the adsorption constant onto the $\mathrm{WO}_{3}$ colloid surface (K') and the aggregation constant on the $\mathrm{WO}_{3}$ colloid surface $\left(K^{\prime}{ }_{\text {agg }}\right)$ are defined as follows:

$$
\begin{aligned}
& \mathrm{XN} \stackrel{K^{\prime}}{=}(\mathrm{XN})_{\mathrm{ad}} \\
& K^{\prime}=\frac{[\mathrm{XN}]_{\mathrm{ad}}}{[\mathrm{XN}]}, \cdots \ldots \ldots \ldots \ldots \ldots . . . . . . . . \\
& n(\mathrm{XN})_{\mathrm{ad}} \stackrel{K_{\mathrm{agg}}^{\prime}}{=}\left\{\left(\mathrm{XN}_{n}\right)\right\}_{\mathrm{ad}} \\
& K_{\mathrm{agg}}^{\prime}=\frac{\left[(\mathrm{XN})_{n}\right]_{\mathrm{ad}}}{[\mathrm{XN}]_{\mathrm{ad}}^{n}}, \cdots \ldots \ldots \ldots . .
\end{aligned}
$$

where $[\mathrm{XN}]$ and $[\mathrm{XN}]_{\mathrm{ad}}$ are the concentration of $\mathrm{XN}$ dye in the aqueous solution and on the $\mathrm{WO}_{3}$ colloid surface, respectively. $\left[(\mathrm{XN})_{n}\right]_{\text {ad }}$ represents the concentration of the aggregate of $\mathrm{XN}$ dyes on the $\mathrm{WO}_{3}$ colloid surface. The subscript or superscript ' $n$ ' is the number of monomer in the unit aggregate. Assuming that the monomer concentration of $\mathrm{XN}$ dyes adsorbed on the $\mathrm{WO}_{3}$ colloid surface is negligibly small, we spectrometrically evaluated the equilibrium concentration of $\mathrm{XN}$ aggregate on the $\mathrm{WO}_{3}$ colloid surface as the following:

$$
\left[(\mathrm{XN})_{n}\right]_{\mathrm{ad}}=\frac{\left([\mathrm{XN}]_{\mathrm{ini}}-[\mathrm{XN}]\right) \cdot V}{n \cdot S}
$$

where the subscript 'ini' denotes initial concentration. $S$ and $V$ are the total surface area of the $\mathrm{WO}_{3}$ colloid (calculated using BET specific area value: $11.8 \mathrm{~m}^{2} \mathrm{~g}^{-132}$ ) and the volume of the aqueous phase, respectively. 
$\left[(\mathrm{XN})_{n}\right]_{\text {ad }}$ can be calculated from the UV-visible spectra at different concentrations using the approximation method of West and Pearce. ${ }^{43}$ Figure 4 show apparent isotherm plots of $\mathrm{XN}$ dyes in the $\mathrm{WO}_{3}$ colloid solution system at $\mathrm{pH} 2$ and 6 . The trend in the behavior of isotherms varied remarkably with the kind of $\mathrm{XN}$ dyes. Furthermore, the only isotherms of RhB, Rh19, and Rh110 having carboxyl group are strongly dependent upon the $\mathrm{pH}$ value of solution. It is clearly that that the presence and kind of substituent groups on the xanthene plane and/or the bottom phenyl ring affect the isotherm behavior. These isotherm shapes were very similar to ones for Langmuir case. However, the Langmuir adsorption isotherm itself does not account for the cooperative/lateral interactions between adsorbed molecules. Since this simple isotherm model was not applicable in the $\mathrm{XN} / \mathrm{WO}_{3}$ aqueous systems, it was modified with the introduction of the aggregation constant term as the following:

$$
\left[(\mathrm{XN})_{n}\right]_{\mathrm{ad}}=\frac{K_{\mathrm{agg}}^{\prime}\left(a K^{\prime}[\mathrm{XN}]\right)^{n}}{\left(a+K^{\prime}[\mathrm{XN}]\right)^{n}}
$$

Herein, $a$ refers to the saturated concentration on the $\mathrm{WO}_{3}$ colloid surface. As shown in Figure 4 , the stoichiometric analysis of the experimental data by using Eq. (6) suggested the aggregation of the dimer $(n=$ 2) of the all $\mathrm{XN}$ dyes on the $\mathrm{WO}_{3}$ colloid surface, meaning that the aggregate formed on the $\mathrm{WO}_{3}$ colloid surface must include two XN dye units as a minimum number. The obtained adsorption and the aggregation parameters of XN dyes are summarized in Table S2 (see Supporting Information). The obtained $K_{\text {agg }}{ }^{\text {values }}$ at same $\mathrm{pH}$ are increased in the order of $\mathrm{Rh} 110<\mathrm{RhB}<\mathrm{Rh} 123<\mathrm{Rh} 3 \mathrm{~B}<\mathrm{Rh} 19<\mathrm{Rh} 6 \mathrm{G}$, which are of the same order as the dimerization constants $\left(K_{\mathrm{d}}\right)$ of $\mathrm{XN}$ dyes in water (see Table $\left.\mathrm{S} 1\right)$. These trends in $\mathrm{XN}$ dyes suggest that the dimerization behavior on the $\mathrm{WO}_{3}$ colloid surface closely resembles the self-dimerization one in water. The $K_{\text {agg }}$ values of $\mathrm{RhB}, \mathrm{Rh} 19$, and $\mathrm{Rh} 110$ exhibit a pronounced dependence upon $\mathrm{pH}$, whereas ones of Rh3B, Rh6G, and Rh123 do not. Meanwhile, the $K^{\prime}$ values exhibit no significant $\mathrm{pH}$ dependence, and are increased in the order of $\mathrm{RhB}<\mathrm{Rh} 3 \mathrm{~B}<\mathrm{Rh} 19<\mathrm{Rh} 6 \mathrm{G}<\mathrm{Rh} 110<\mathrm{Rh} 123$. Thus, the adsorptivity of $\mathrm{XN}$ dyes is approximately irrelevant to the proton dissociation of carboxyl group on the bottom phenyl ring. 
Moreover, the XN dyes with the ethyl substituent(s) on peripheral amino groups have smaller $K^{\prime}$ values than ones without the ethyl substituent. The effect of the peripheral substituent(s) on the adsorption behavior to the $\mathrm{WO}_{3}$ colloid surface is apparent. It is noted that the adsorptivity of $\mathrm{XN}$ dyes is not depended upon the aggregate activity on the $\mathrm{WO}_{3}$ colloid surface. A similar tendency has been previously reported by us for phenothiazine dye molecules adsorbed on the $\mathrm{WO}_{3}$ colloid surface. ${ }^{21}$

Moreover, in order to explicate the detail adsorption mechanism of the $\mathrm{XN}$ dyes onto the $\mathrm{WO}_{3}$ colloid surface, the influence of ionic strength on the isotherm was also investigated under a constant $\mathrm{XN}$ dye concentration. As can be seen in Table S3 (see Supporting Information), the adsorption constants of XN dyes decreased with increasing in the sodium sulfate concentration. Such a tendency clearly reveals that the adsorption phenomenon of $\mathrm{XN}$ dye on the $\mathrm{WO}_{3}$ colloid surface is driven by the electrostatic interaction between cationic or zwitterionic $\mathrm{XN}$ dye molecules and negative-charged $\mathrm{WO}_{3}$ colloid surface. Taking the observed $a$ value of $\mathrm{XN}$ dyes, the area per molecule on the $\mathrm{WO}_{3}$ colloid surface can be determined for every $\mathrm{XN} / \mathrm{WO}_{3}$ aqueous system, which is also listed in Table $\mathrm{S} 2$. For cationic $\mathrm{XN} / \mathrm{WO}_{3}$ aqueous system, similar molecular area values were calculated, which varied between 37.7 and $43.5 \AA^{2} /$ molecule. Because these experimental values are quite close to the projection area ones (estimated from the CPK model optimized at PM3 level with Hyperchem program ${ }^{44}$ ) of the $\mathrm{XN}$ derivatives lying edge-on (see Figure 4(g)), a perpendicular standing structure would be assumed for a monolayer adsorption/aggregation morphology of cationic $\mathrm{XN}$ dyes on the $\mathrm{WO}_{3}$ colloid surface. Interestingly, the area per molecule in the zwitterionic $\mathrm{XN} / \mathrm{WO}_{3}$ aqueous systems was calculated to be $78.2-85.1 \AA^{2} /$ molecule (see Table S2), which is approximately two-fold larger than that in the cationic $\mathrm{XN} / \mathrm{WO}_{3}$ aqueous systems. In addition, these values are bigger than the projection area ones of the $\mathrm{XN}$ dyes lying edge-on, but much smaller than the ones with a monomeric xanthene skeleton facing on surface (see Figure $4(\mathrm{~g})$ ), so that the zwitterionic XN dyes would be somewhat tilted with respect to the $\mathrm{WO}_{3}$ surface. Overall, a remarkable difference was observed between the cationic and zwitterionic $\mathrm{XN}$ dyes upon adsorbing on the $\mathrm{WO}_{3}$ colloid surface, indicating the electrostatic 
(attractive/repulsive) interaction between two $\mathrm{XN}$ dye molecules on the surface, as also shown in many previous studies on supramolecular systems on surfaces. ${ }^{45,46}$

The observed blue- and red-shift for $\mathrm{XN}$ dyes by $\mathrm{WO}_{3}$ colloid titration are resulted from the sum absorption of dimerized ones on $\mathrm{WO}_{3}$ colloids and unadsorbed ones in the aqueous solution. Using the $K^{\prime}$ and $K^{\prime}$ agg values calculated from Eq. (6), we can pursue global least-squares analysis to establish the pure dimer spectra in the $\mathrm{XN} / \mathrm{WO}_{3}$ aqueous system. Figure 5 shows the resolved monomer and dimer spectra of cationic and zwitterionic XN dyes. Unlike the pure dimer spectra of cationic XN dyes in water (see Figure 2), the dimer absorption spectra of cationic ones in the $\mathrm{WO}_{3}$ colloid aqueous solution appear likely to contain only one strong blue-shifted band relative to the monomer absorption, because red-shifted ones' intensity is relatively very weak. On the other hand, in the zwitterionic $\mathrm{XN} / \mathrm{WO}_{3}$ aqueous system, a prominent bandsplitting into weak blue-shifted and strong red-shifted absorption components is observed, as shown in Figure 5(b), (e), and (h). This shifting and splitting of the absorption band would be very important in understanding a nanostructure of the aggregate of cationic and zwitterionic $\mathrm{XN}$ dyes adsorbed on the $\mathrm{WO}_{3}$ colloid surface, and potentially aid in development of novel self-assembled nanoscale architecture on metal oxide as nano-templates or supports. We will have more to say on the difference in the adsorptionaggregation mechanism of cationic and zwitterionic XN dyes in the below section 3.4. 


\section{3. pH-Induced Switch between $H$ - and $J$-Aggregation Mode of $\mathrm{XN}$ Dyes Stacks on the $\mathrm{WO}_{3}$ Colloid Surface.}

Spectroscopic discrimination between the $H$ - and $J$-dimerization mode of $\mathrm{XN}$ dyes with carboxyl group on the bottom phenyl ring ( $\mathrm{RhB}, \mathrm{Rh} 19$, and $\mathrm{Rh} 110)$ was achieved by UV-visible absorption spectral examinations. It is intriguing to find that the dye aggregates formed on the metal oxide could be transformed depending upon pH. Figure 6(a), (b), and (c) show the UV-visible spectral changes of RhB, Rh19, and Rh110, respectively, in the $\mathrm{WO}_{3}$ colloid solution under various $\mathrm{pH}$ conditions. The insets show changes of the maximum molar extinction coefficient in $H$ - and $J$-bands depending upon the $\mathrm{pH}$ values in $\mathrm{XN} / \mathrm{WO}_{3}$ aqueous system. For instance, upon increasing $\mathrm{pH}$ value from 2 to 6 , the color of the $\mathrm{RhB} / \mathrm{WO}_{3}$ binary aqueous solution changed from bright-red to purplish-red. In the corresponding spectrum in the $\mathrm{RhB} / \mathrm{WO}_{3}$ aqueous system, the $\mathrm{RhB} H$-dimer band at $528 \mathrm{~nm}$ was observed to disappear, and then a new one $J$-dimer band at $569 \mathrm{~nm}$ appeared in the region higher than $\mathrm{pH} \mathrm{3}$, as shown in Figure 6(a). The isosbestic point observed in Figure 6(a) would imply a stoichiometric conversion between $\mathrm{RhB} H$-dimer and $J$-dimer on $\mathrm{WO}_{3}$ colloid surface. Moreover, this $\mathrm{pH}$ titration was carried out over several cycles using the same $\mathrm{RhB} / \mathrm{WO}_{3}$ colloid solution, and the absorption spectrum was recorded after each step (pH 2 and 6). As shown in Figure 6(d), the changes of the molar extinction coefficient at 528 and $569 \mathrm{~nm}$ demonstrated the high degree of reversibility of the $\mathrm{pH}$-induced switching process between $\mathrm{RhB} H$-dimer and $J$-dimer. As may be seen from Figure 6, similar $\mathrm{pH}$ dependency and responsivity were obtained in the both aqueous solution of $\mathrm{Rh} 19 / \mathrm{WO}_{3}$ and $\mathrm{Rh} 110 / \mathrm{WO}_{3}$. It is noted that the drastic aggregation mode change of $\mathrm{XN}$ dye dimers formed on the $\mathrm{WO}_{3}$ colloid surface was induced reversibly in response to external stimuli, that is, depending upon $\mathrm{pH}$ values of surrounding water medium. The results clearly demonstrate the dye's reversible interconversion between the $H$ - and $J$-aggregation modes on the metal oxide nanoparticles. 


\subsection{Static Aggregate Geometry of XN Dyes in Water and on the $\mathrm{WO}_{3}$ Colloid Surface.}

It is prominent that $\mathrm{XN}$ dyes have various molecular forms which depend upon the concentration of the solution, and that ones willingly form dimers in aqueous solution. Additionally, various aggregation states of $\mathrm{XN}$ dyes in the $\mathrm{WO}_{3}$ colloid solution were detected depending on the $\mathrm{pH}$ condition, as described above section. As shown in the lowest part of Scheme 1, the XN dyes used in this study have a planar xanthene skeleton with a phenyl ring that is perpendicular to the skeleton. The strong electric dipole transition moment $(500-600 \mathrm{~nm})$ of the $\mathrm{XN}$ dye is parallel to the long axis of the xanthene skeleton, ${ }^{47,48}$ as shown by the arrow. The phenyl ring is able to swivel around the phenyl-xanthene bond, and the carboxyl/carboxyl-ester group can swing around the carbon-carbon bond.

The molecular orbital overlap between two or more chromophores that bring interaction between the excited states eventually leads to their splitting described by Kasha's exciton coupling model built on the electrostatic interaction approximation of the point transition dipoles in the excited state. ${ }^{8,49,50}$ Based on this model, exciton coupling between closely stacked chromophores causes changes in the optical spectra. The energy gaps and the transition probabilities from the ground states to these excited states depend on the relative orientation of the transition moment vector of the monomeric units in the aggregate. It has been pointed out that the shifts of the absorption maximum with respect to that of the monomer can occur depending upon the angle between the direction of the dipolar moments and the line linking the molecular centers (slipping angle: $\theta$ ) and the angle between the transition moments of the monomers in the aggregate (twisting angle: $\alpha$ ). As shown in Scheme 2, the allowed transition energy gap is larger than that of the monomer for face-to-face stacked chromophores $\left(54.7^{\circ}<\theta \leq 90^{\circ}\right.$ and $\alpha=0 ; H$-type aggregate) and smaller than that for head-to-tail arranged chromophores $\left(0^{\circ} \leq \theta<54.7^{\circ}\right.$ and $\alpha=0 ; J$-type aggregate), corresponding to a blue-shifted band ( $H$-band) and a red-shifted band ( $J$-band), respectively. On the other hand, twisted face-to-face $\left(54.7^{\circ}<\theta \leq 90^{\circ}\right.$ and $\left.0^{\circ}<\alpha \leq 90^{\circ}\right)$ and oblique head-to-tail aggregates $\left(0^{\circ} \leq \theta<54.7^{\circ}\right.$ and $0^{\circ}<\alpha \leq$ $90^{\circ}$ ) have been proposed for the aggregate geometry that gives the both $H$ - and $J$-bands. In these cases, given 
that the $J$-band intensity is smaller or higher than the $H$-band one, we have definite evidence for the twisted face-to-face or oblique head-to-tail fashion, respectively. Namely, the values of twisting angle $\alpha$ can be determined using the relative strengths of the $H$ - and $J$-bands. Assuming that the distance between transition dipoles of the $\mathrm{XN}$ dye molecules is constant, the twisting angle between the dipoles in the aggregate can be evaluated using: $:^{51-54}$

$$
\tan ^{2} \frac{\alpha}{2}=\frac{f_{\mathrm{J}}}{f_{\mathrm{H}}}
$$

where $f_{\mathrm{H}}$ and $f_{\mathrm{J}}$ are oscillator strengths of the $H$ - and $J$-bands, respectively, of the aggregates. Generally, the oscillator strength, $f$, is defined by the integral over the molar extinction coefficients, $\varepsilon(v):^{55}$

$$
f=4.32 \times 10^{-9} \int_{0}^{\infty} \varepsilon(v) \mathrm{d} v
$$

The $\alpha$ values for the $\mathrm{XN}$ dye dimers formed in water and on the $\mathrm{WO}_{3}$ colloid surface are calculated from pure dimer spectra as shown in Figures 2 and 5, and also listed in Table S1 and S2, respectively. As a comparable case, we hereby focus on the results of $\mathrm{RhB}$ and $\mathrm{Rh} 3 \mathrm{~B}$, where the main difference is only either the carboxyl $(-\mathrm{COOH})$ or carboxyl-ethylester $(-\mathrm{COOEt})$ group, respectively, in the pendent phenyl ring (perpendicular to the xanthene plane, see Scheme 1). The carboxyl group in cationic RhB dissociates in neutral aqueous solutions, leading a zwitterionic RhB. As evident from Figure 2, the deconvoluted dimer spectra indicate that the $\mathrm{RhB}$ and $\mathrm{Rh} 3 \mathrm{~B}$ dimer geometry in water has a declination from an accurate face-to-face stacking arrangement of the dye molecular planes. Indeed, the results from Eq. (7) suggested that the transition dipoles of both cationic $\mathrm{RhB}$ and $\mathrm{Rh} 3 \mathrm{~B}$ molecules in the $H$-dimer species formed in acidic water (pH 2) are aligned, with respect to each other, through a twisting angle $\alpha=$ ca. $60^{\circ}$. Only zwitterionic $\mathrm{RhB}$ molecules in neutral water $\left(\mathrm{pH}\right.$ ) adopt a face-to-face dimer arrangement with a twisting angle of $\alpha=\mathrm{ca} .70^{\circ}$ (see Table S1). A noteworthy finding in this analysis is that zwitterionic RhB dimer in neutral water is more twisted than cationic $\mathrm{RhB}$ and $\mathrm{Rh} 3 \mathrm{~B}$ ones in acidic water (compare twist angles $\alpha$ in Table S1). Generally, it is believed that interactions between the $\pi$-electron clouds, viz. the $\pi$ - $\pi$ stacking, influence to the aggregate 
structures of molecules. ${ }^{56}$ While such $\pi$-electron interactions may contribute to the twist in the RhB and Rh3B dimers, it likely is not the major contributor to the twist variance. Scheme 3(a) highlights the difference in structure between the cationic and zwitterionic $\mathrm{RhB}$ dimers formed in water. The various electrostatic attractive/repulsive interactions between charged dye molecules in the dimer species also would exist, because RhB molecules exist as cations or zwitterions in an aqueous solution. The positive-charged peripheral amino groups on the two cationic $\mathrm{RhB}$ or $\mathrm{Rh} 3 \mathrm{~B}$ molecules may be aligned as to achieve a chargeseparated conformation with a certain twisting angle. Meanwhile, in the case of zwitterionic RhB dimer, granted that the counter interactions contribute to the dimer arrangement, we should also consider the attractive interaction between positive amine and negative carboxyl groups. Consequently, the dimer of zwitterionic $\mathrm{RhB}$ molecules would be more twisted than the dimer of cationic ones.

The different environment of $\mathrm{XN}$ dye's dimer in water or on the $\mathrm{WO}_{3}$ colloid surface determines the observed spectroscopic differences. Among others, from the analyses in the $\mathrm{RhB} / \mathrm{WO}_{3}$ and $\mathrm{Rh} 3 \mathrm{~B} / \mathrm{WO}_{3}$ aqueous system, more intriguingly, a significant difference in the dimer configuration was found. As seen in Figure 5 and Table 2, the both calculated $\alpha$ values of cationic $\mathrm{RhB}$ and $\mathrm{Rh} 3 \mathrm{~B} H$-dimers formed on the $\mathrm{WO}_{3}$ colloid surface are about $10^{\circ}$. Only zwitterionic RhB molecules readily form $J$-dimers with a twisting angle of $\alpha=c a .60^{\circ}$ on the $\mathrm{WO}_{3}$ colloid surface. The formation of $H$-dimers or $J$-dimers is also meant to be related to the adsorption geometry adopted by the $\mathrm{RhB}$ molecules on the $\mathrm{WO}_{3}$ colloid surface. Thus, from the joint evidence provided by Langmuir adsorption model (molecular occupied area) and exciton coupling theory (slipping and twisting angles), we hypothesize the probable model for the adsorption-dimerization of cationic $\mathrm{Rh} 3 \mathrm{~B}$ and cationic/zwitterionic $\mathrm{RhB}$ on the $\mathrm{WO}_{3}$ colloid surface, as shown in Scheme 3(b). The small molecular occupied area and small twisting angle of $H$-dimers formed on the $\mathrm{WO}_{3}$ colloid surface clearly imply that the electrostatic interaction between cationic $\mathrm{RhB}$ or $\mathrm{Rh} 3 \mathrm{~B}$ and negative-charged $\mathrm{WO}_{3}$ colloid surface tends to be edge-on (perpendicular) adsorption, and eventually results in the approximately ideal face-to-face $\pi$-stacked geometry without the electrostatic repulsive interactions, because the excess of 
negative-charges on the $\mathrm{WO}_{3}$ colloid surface minimizes the electrostatic repulsions between cationic amino groups in the adsorbed $\mathrm{RhB}$ or Rh3B molecules. Unlike cationic $\mathrm{RhB}$ and $\mathrm{Rh} 3 \mathrm{~B}$, zwitterionic $\mathrm{RhB}$ molecules adsorbed on the $\mathrm{WO}_{3}$ colloid surface are assembled into the oblique head-to-tail $J$-dimers, in which the xanthene skeletons are somewhat leaned against each other and the peripheral cationic amine's edges are facing the negative-charged surface, suggesting that the formation of the face-to-face $H$-dimers is suppressed by each of deprotonated carboxyl groups on the bottom phenyl ring because of electrostatic repulsive interaction. Similar phenomena occur in the other $\mathrm{XN} / \mathrm{WO}_{3}$ aqueous systems containing cationic or zwitterionic Rh19 or Rh110. In our study, the cationic Rh6G and Rh123 did not also exhibit $J$-aggregation patterns in the $\mathrm{WO}_{3}$ colloid aqueous solution. Overall, in the $\mathrm{XN} / \mathrm{WO}_{3}$ aqueous system, the carboxyl group in the $\mathrm{XN}$ dye could induce transformation of the geometry from $\mathrm{H}$-dimer (face-to-face fashion) to $J$-dimer (head-to-tail fashion) and vice versa, whereas when the carboxyl-ester group was applied in the XN dye, only $H$-dimers were observed. Additionally, as described in the lower part of Figure 6, the reversible switching between the $H$ - and $J$-aggregation modes depending upon $\mathrm{pH}$ value in the $\mathrm{XN} / \mathrm{WO}_{3}$ aqueous systems supports this balanced electrostatic attractive/repulsive interaction for the aggregation behaviors on the $\mathrm{WO}_{3}$ colloid surface. Of course, we understand that this is only a speculation, and further studies of other cationic/zwitterionic dyes are needed to confirm these findings. 


\section{CONCLUSION}

The adsorption and aggregation phenomena of six xanthene $(\mathrm{XN})$ dyes having the carboxyl group [rhodamine B (RhB), rhodamine 19 (Rh19), and rhodamine 110 (Rh110)] or carboxyl-ester group [rhodamine 3B (Rh3B), rhodamine 6G (Rh6G), and rhodamine 123 (Rh123)] on the pendant phenyl ring were spectrophotometrically investigated in the $\mathrm{WO}_{3}$ colloid aqueous solution. Addition of the $\mathrm{WO}_{3}$ colloid aqueous solution into the $\mathrm{XN}$ dye aqueous solution brought about significant changes in the absorption spectrum due to a strong self-dimerization via the electrostatic adsorption onto negatively charged $\mathrm{WO}_{3}$ colloid surface. The detail data analysis of the spectra suggests that the presence of methyl groups on the xanthene skeleton results in an increase of the dimerization constant probably due to van der Waals attractive interaction, while the ethyl substituent(s) on the peripheral amino groups suppresses the adsorptivity onto the $\mathrm{WO}_{3}$ colloid surface because of steric repulsive interaction, as already reported for the phenothiazine compounds which are structural analogues of xanthene. ${ }^{21}$ Although "zwitterionic" RhB, Rh19, or Rh110 molecules adsorbed on the $\mathrm{WO}_{3}$ colloid surface tend to $\pi$-stack into $J$-dimer (head-to-tail fashion), "cationic" $\mathrm{RhB}, \mathrm{Rh} 19, \mathrm{Rh} 110, \mathrm{Rh} 3 \mathrm{~B}, \mathrm{Rh} 6 \mathrm{G}$, or Rh123 ones adsorbed favor $H$-dimer (face-to-face fashion). It is obvious that the proton dissociation of carboxyl group on the pendant phenyl ring plays an important role in their dimer geometries on the surface, because no $J$-dimers of the cationic Rh3B, Rh6G, and Rh123 were observed in the $\mathrm{WO}_{3}$ colloid aqueous solution irrespective of the $\mathrm{pH}$ values used in this study (pH 2 6). Additionally, the present study demonstrates the feasibility of designing $\mathrm{pH}$-induced switchable $\mathrm{XN}$ dye aggregate geometry from $H$-dimer to $J$-dimer and vice versa on the $\mathrm{WO}_{3}$ colloid surface. We believe that the concept of the multiple balanced non-covalent interactions ( $\pi-\pi$ stacking, van der Waals, steric-hindrance, and/or electrostatic attractive/repulsive interactions) between the organic dyes as well as between the dyes and surface has high potential utility in the building up of supramolecular systems on the metal oxide surface. Through the use of this tactic, we envisage new applications of this model in the development of tunable 
solid-state dye lasers and advanced dye-sensitized solar cells, where the adsorption/aggregation morphology of organic dyes on the metal oxide is a crucial factor to be considered. Further related work is in progress. 


\section{ACKNOWLEDGEMENT}

This study was partially supported by the Scientific Research of the Grant-in-Aid for Young Scientists (B) (No. 24750069) from Japan Society for the Promotion of Science (JSPS). ICP-AES and TEM measurements documented in this study were performed at the Center for Instrumental Analysis and the Innovation Center, respectively, Yamaguchi University.

\section{SUPPORTING INFORMATION AVAILABLE}

TEM images of the $\mathrm{WO}_{3}$ colloid particles; $\mathrm{pH}$-dependence of UV-visible absorption spectra of the $\mathrm{XN}$ dyes in water; additional parameters of $\mathrm{XN}$ dye's aggregates formed on the $\mathrm{WO}_{3}$ colloid surface. This information is available free of charge via the Internet at http://pubs.acs.org. 


\section{REFERENCES}

(1) Gaufrès, E.; Tang, N.Y.-W.; Lapointe, F.; Cabana, J.; Nadon, M.-A.; Cottenye, N.; Raymond, F.; Szkopek, T.; Martel, R. Giant Raman scattering from J-aggregated dyes inside carbon nanotubes for multispectral imaging. Nat. Photonics, 2014, 8, 72-78.

(2) Li, H.; Frigaard, N.-U.; Bryant, D.A. Molecular Contacts for Chlorosome Envelope Proteins Revealed by Cross-Linking Studies with Chlorosomes from Chlorobium tepidum. Biochemistry, 2006, 45, 9095-9103.

(3) Adachi, K.; Chayama, K.; Watarai, H. Formation of Helical J-Aggregate of Chiral ThioetherDerivatized Phthalocyanine Bound by Palladium(II) at the Toluene/Water Interface. Langmuir, 2006, $22,1630-1639$.

(4) Prince, S.M; Papiz, M.Z.; Freer, A.A.; McDermott, G.; Hawthornthwaite-Lawless, A.M.; Cogdell, R.J.; Isaacs, N.W. Apoprotein structure in the LH2 complex from Rhodopseudomonas acidophila strain 10050: modular assembly and protein pigment interactions. J. Mol. Biol., 1997, 268, 412-423.

(5) Scheer, H. (Ed.) Chlorophylls, CRC Press: Florida, USA, 1991.

(6) Hamblin, M.R.; Hasan, T. Photodynamic therapy: A new antimicrobial approach to infectious disease? Photochem. Photobiol. Sci., 2004, 3, 436-450.

(7) Drain, C.M.; Varotto, A.; Radivojevic, I. Self-Organized Porphyrinic Materials. Chem. Rev., 2009, $109,1630-1658$.

(8) Kasha, M.; Rawls, H.R.; Bayoumi, M.A. Exciton model in molecular spectroscopy. Pure Appl. Chem., 1965, 11, 371-392.

(9) Arai, Y.; Segawa, H. J-Aggregation of protonated meso-tetrakis(sulfonatothienyl)porphyrin isomers: Morphological selection of self-assembled nanostructures from structurally similar zwitterionic porphyrins. Chem. Commun., 2010, 46, 4279-4281.

(10) Yamamoto, S.; Watarai, H. Counterion-Dependent Morphology of Porphyrin Aggregates Formed at the Liquid/Liquid Interface Studied by Total Internal Reflection Resonant Rayleigh and Raman Scattering Microscopy. J. Phys. Chem. C, 2008, 112, 12417-12424.

(11) Aggarwal, L.P.F.; Borissevitch, I.E. On the dynamics of the TPPS 4 aggregation in aqueous solutions: Successive formation of H and J aggregates. Spectrochim. Acta A, 2006, 63, 227-233.

(12) Feringa, B.L.; Browne, W.R. (Eds.) Molecular Switches; Wiley-VCH, Weinheim, Germany, 2011.

(13) Atwood, J.L.; Steed, J.W. (Eds.) Encyclopedia of Supramolecular Chemistry, Marcel Dekker: New York, USA, 2004. 
(14) Sanchez, C.; Rozes, L.; Ribot, F.; Laberty-Robert, C.; Grosso, D.; Sassoye, C.; Boissiere, C.; Nicole, L. "Chimie douce": A land of opportunities for the designed construction of functional inorganic and hybrid organic-inorganic nanomaterials. C. R. Chimie., 2010, 13, 3-39.

(15) Daniel, M.-C.; Astruc, D. Gold Nanoparticles: Assembly, Supramolecular Chemistry, Quantum-SizeRelated Properties, and Applications toward Biology, Catalysis, and Nanotechnology. Chem. Rev., 2004, 104, 293-346.

(16) Reddy, K.G.; Deepak, T.G.; Anjusree, G.S.; Thomas, S.; Vadukumpully, S.; Subramanian, K.R.V.; Nair, S.V.; Nair, A.S. On global energy scenario, dye-sensitized solar cells and the promise of nanotechnology. Phys. Chem. Chem. Phys., 2014, 16, 6838-6858.

(17) Gong, J.; Liang, J.; Sumathya, K. Review on dye-sensitized solar cells (DSSCs): Fundamental concepts and novel materials. Renew. Sust. Energ. Rev., 2012, 16, 5848-5860.

(18) Zhang, Q.; Atay, T.; Tischler, J.R.; Bradley, M.S.; Bulović, V.; Nurmikko, A.V. Highly efficient resonant coupling of optical excitations in hybrid organic/inorganic semiconductor nanostructures. Nat. Nanotechnol., 2007, 2, 555-559.

(19) Rochford, J.; Chu, D.; Hagfeldt, A.; Galoppini, E. Tetrachelate Porphyrin Chromophores for Metal Oxide Semiconductor Sensitization: Effect of the Spacer Length and Anchoring Group Position. J. Am. Chem. Soc., 2007, 129, 4655-4665.

(20) Kanetada, N.; Matsumura, C.; Yamazaki, S.; Adachi, K. Mechanism of Peripheral Substituent Effects on Adsorption-Aggregation Behaviors of Cationic Porphyrin Dyes on Tungsten(VI) Oxide Nanocolloid Particles. ACS Appl. Mater. Interfaces, 2013, 5, 12991-12999.

(21) Adachi, K.; Mita, T.; Yamate, T.; Yamazaki, S.; Takechi, H.; Watarai, H. Controllable Adsorption and Ideal H-Aggregation Behaviors of Phenothiazine Dyes on the Tungsten Oxide Nanocolloid Surface. Langmuir, 2010, 26, 117-125.

(22) Beija, M.; Afonso, C.A.M.; Martinho, J.M.G. Synthesis and applications of Rhodamine derivatives as fluorescent probes. Chem. Soc. Rev., 2009, 38, 2410-2433.

(23) Zhang, J.; Sun, L.; Ichinose, K.; Funabiki, K.; Yoshida, T. Effect of Anchoring Groups on Electrochemical Self-Assembly of $\mathrm{ZnO} /$ Xanthene Dye Hybrid Thin Films. Phys. Chem. Chem. Phys., 2010, 12, 10494-10502.

(24) Granqvist, C.G. Electrochromic tungsten oxide films: Review of progress 1993-1998. Sol. Energy Mater. Sol. Cells, 2000, 60, 201-262. 
(25) Bamwenda, R.G.; Sayama, K.; Arakawa, H. The effect of selected reaction parameters on the photoproduction of oxygen and hydrogen from a $\mathrm{WO}_{3}-\mathrm{Fe}^{2+}-\mathrm{Fe}^{3+}$ aqueous suspension. J. Photochem. Photobiol. A, 1999, 122, 175-183.

(26) Yamase, T. Photo- and Electrochromism of Polyoxometalates and Related Materials. Chem. Rev., 1998, $98,307-325$.

(27) Zheng, H.; Ou, J.Z.; Strano, M.S.; Kaner, R.B.; Mitchell, A.; Kalantar-zadeh, K. Nanostructured Tungsten Oxide - Properties, Synthesis, and Applications. Adv. Funct. Mater., 2011, 21, 2175-2196.

(28) Tanaka, S.; Adachi, K.; Yamazaki, S. Surface-enhanced photochromic phenomena of phenylalanine adsorbed on tungsten oxide nanoparticles: a novel approach for "label-free" colorimetric sensing. Analyst, 2013, 138, 2536-2539.

(29) He, Y.; Wu, Z.; Fu, L.; Li, C.; Miao, Y.; Cao, L.; Fan, H.; Zou, B. Photochromism and Size Effect of $\mathrm{WO}_{3}$ and $\mathrm{WO}_{3}-\mathrm{TiO}_{2}$ Aqueous Sol. Chem. Mater., 2003, 15, 4039-4045.

(30) Barrett, E.P.; Joyner, L.G.; Halenda, P.P. The Determination of Pore Volume and Area Distributions in Porous Substances. I. Computations from Nitrogen Isotherms. J. Am. Chem. Soc., 1951, 73, 373380.

(31) Brunauer, S. The Adsorption of Gases and Vapors, Oxford Univ. Press, Oxford, UK, 1944.

(32) Adachi, K.; Tanaka, S.; Yamazaki, S.; Takechi, H.; Tsukahara, S.; Watarai, H. Chirality induction and amplification in methylene blue H-aggregates via D- and L-phenylalanine pre-adsorbed on the tungsten oxide nanocolloid surface. New J. Chem., 2012, 36, 2167-2170.

(33) López Arbeloa, I. Dimeric and trimeric states of the fluorescein dianion. Part 1.--Molecular structures. J. Chem. Soc., Faraday Trans. 2, 1981, 77, 1725-1733.

(34) López Arbeloa, I.; Ruiz Ojeda, P. Dimeric states of rhodamine B. Chem. Phys. Lett., 1982, 87, 556560.

(35) Casalini, T.; Salvalaglio, M.; Perale, G.; Masi, M.; Cavallotti, C. Diffusion and Aggregation of Sodium Fluorescein in Aqueous Solutions. J. Phys. Chem. B, 2011, 115, 12896-12904.

(36) Fujii, T.; Nishikiori, H.; Tamura, T. Absorption spectra of rhodamine B dimers in dip-coated thin films prepared by the sol-gel method. Chem. Phys. Lett., 1995, 233, 424-429.

(37) Nishikiori, H.; Fujii, T. Molecular Forms of Rhodamine B in Dip-Coated Thin Films. J. Phys. Chem. $B, 1997,101,3680-3687$.

(38) Moreno-Villoslada, I.; Fuenzalida, J.P.; Tripailaf, G.; Araya-Hermosilla, R.; Pizarro, G.C.; Marambio, O.G.; Nishide, H. Comparative Study of the Self-Aggregation of Rhodamine 6G in the Presence of 
Poly(sodium 4-styrenesulfonate), Poly(N-phenylmaleimide-co-acrylic acid), Poly(styrene-alt-maleic acid), and Poly(sodium acrylate). J. Phys. Chem. B, 2010, 114, 11983-11992.

(39) Arbeloa, F.L.; Gonzalez, I.L.; Ojeda, P.R.; Arbeloa, I.L. Aggregate formation of rhodamine 6G in aqueous solution. J. Chem. Soc., Faraday Trans. 2, 1982, 78, 989-994.

(40) Sariri, R.; Zakerhamidi, M.S.; Baharpaima, K.; Ghanadzadeh, A. The anion effect and molecular association of rhodamine dyes in isotropic and anisotropic solvents. J. Mol. Liq., 2004, 115, 55-61.

(41) Parks, G.A. The Isoelectric Points of Solid Oxides, Solid Hydroxides, and Aqueous Hydroxo Complex Systems. Chem. Rev., 1965, 65, 177-198.

(42) Kosmulski, M. Chemical Properties of Material Surfaces, Marcel Dekker Inc.: New York, USA, 2001.

(43) West, W.; Pearce, S. The Dimeric State of Cyanine Dyes. J. Phys. Chem., 1965, 69, 1894-1903.

(44) Hyperchem 7.5 for Windows; Hypercube, Inc., 2003.

(45) Yu, Y.; Anthony, S.M.; Zhang, L.; Bae, S.C.; Granick, S. Cationic Nanoparticles Stabilize Zwitterionic Liposomes Better than Anionic Ones. J. Phys. Chem. C, 2007, 111, 8233-8236.

(46) Espinosa-Jiménez, M.; Giménez-Martín, E.; Ontiveros-Ortega, A. Effect of Tannic Acid on the zeta Potential, Sorption, and Surface Free Energy in the Process of Dyeing of Leacril with a Cationic Dye. J. Colloid Interface Sci., 1998, 207, 170-179.

(47) Geddes, C.D. (Ed.) Reviews in Fluorescence 2008, Springer: New York, USA, 2010.

(48) Vosgrçne, T.; Meixner, A.J. Surface- and Resonance-Enhanced Micro-Raman Spectroscopy of Xanthene Dyes: From the Ensemble to Single Molecules. ChemPhysChem, 2005, 6, 154-163.

(49) Kobayashi, T. (Ed.) J-aggregates, World Scientific Publishing: Singapore (1996).

(50) Kobayashi, T. (Ed.) J-aggregates Vol. 2, World Scientific Publishing: Singapore (2012).

(51) Carbonaro, C.M.; Ricci, P.C.; Grandi, S.; Marceddu, M.; Corpino, R.; Salis, M.; Anedda, A. On the formation of aggregates in silica-rhodamine 6G type II hybrids. RSC Adv., 2012, 2, 1905-1912.

(52) Ferrer, M.L.; del Monte, F.; Levy, D. Rhodamine 19 Fluorescent Dimers Resulting from Dye Aggregation on the Porous Surface of Sol-Gel Silica Glasses. Langmuir, 2003, 19, 2782-2786.

(53) Fidder, H. Absorption and emission studies on pure and mixed J-aggregates of pseudoisocyanine. Chem. Phys., 2007, 341, 158-168.

(54) Arbeloa, F.L.; Chaudhuri, R.; López, T.A.; Arbeloa, I.L. Aggregation of Rhodamine 3B Adsorbed in Wyoming Montmorillonite Aqueous Suspensions. J. Colloid Interface Sci., 2002, 246, 281-287. 
(55) Zawadzka, A.; Płóciennik, P.; Czarnecka, I.; Sztupecka, J.; Łukasiak, Z. The effects of annealing process influence on optical properties and the molecular orientation of selected organometallic compounds thin films. Opt. Mater., 2012, 34, 1686-1691.

(56) Schneider, H.-J. Applications of Supramolecular Chemistry, CRC Press: Florida, USA, 2012. 


\section{Figure Captions}

Figure 1 Concentration dependence of UV-visible absorption spectrum of (a) cationic RhB, (b) zwitterionic RhB, (c) cationic Rh3B, (d) cationic Rh19, (e) zwitterionic Rh19, (f) cationic Rh6G, (g) cationic Rh110, (h) zwitterionic Rh110, and (i) cationic Rh123 in water at $25^{\circ} \mathrm{C}$. Concentration conditions: $[\mathrm{XN}$ dye $]=(\mathrm{A}) 1.0 \times 10^{-6} \mathrm{M}$, (B) $1.0 \times 10^{-5} \mathrm{M},(\mathrm{C}) 2.0 \times 10^{-5} \mathrm{M}$, (D) $3.0 \times 10^{-5} \mathrm{M}$, (E) $5.0 \times 10^{-4} \mathrm{M}$, (F) $1.0 \times 10^{-3} \mathrm{M}$; $\left[\mathrm{Na}_{2} \mathrm{SO}_{4}\right]=3.3 \times 10^{-2} \mathrm{M} ; \mathrm{pH} 2$ (cationic condition), $\mathrm{pH} 6$ (zwitterionic condition). The arrows indicate the direction of the absorbance changes with increasing concentration. The insets show molar extinction coefficient $(\varepsilon)$ of each $\mathrm{XN}$ dye at the monomer absorption peak at various concentrations in water. The solid lines are the best fit of the data to Eq.(1).

Figure 2 Resolved pure monomer and dimer spectra of (a) cationic $\mathrm{RhB}$, (b) zwitterionic $\mathrm{RhB}$, (c) cationic Rh3B, (d) cationic Rh19, (e) zwitterionic Rh19, (f) cationic Rh6G, (g) cationic Rh110, (h) zwitterionic Rh110, and (i) cationic Rh123 in water at $25^{\circ} \mathrm{C}$.

Figure 3 Change of UV-visible absorption spectra of (a) cationic $\mathrm{RhB}$, (b) zwitterionic $\mathrm{RhB}$, (c) cationic Rh3B, (d) cationic Rh19, (e) zwitterionic Rh19, (f) cationic Rh6G, (g) cationic Rh110, (h) zwitterionic Rh110, and (i) cationic Rh123 aqueous solution as a function of added $\mathrm{WO}_{3}$ colloid. Concentration conditions: $[\mathrm{XN}$ dye $]=1.0 \times 10^{-6} \mathrm{M} ;\left[\mathrm{Na}_{2} \mathrm{SO}_{4}\right]=3.3 \times 10^{-2} \mathrm{M} ; \mathrm{pH} 2$ (cationic condition), $\mathrm{pH} 6$ (zwitterionic condition); molar ratios ([ $\left.\mathrm{WO}_{3}\right] /[\mathrm{XN}$ dye $]$ ) as follows: (A) 0, (B) 0.5, (C) 1, (D) 2, (E) 4, (F) 10, (G) 40, (H) 100. The arrows indicate the direction of the absorbance changes, as the $\mathrm{WO}_{3}$ colloid concentration is increased.

Figure 4 Adsorption isotherms of (a) RhB, (b) Rh19, (c) Rh110, (d) Rh3B, (e) Rh6G, and (f) Rh123 on the $\mathrm{WO}_{3}$ colloid surface. Concentration conditions: $[\mathrm{XN}$ dye $]=1.0 \times 10^{-6} \mathrm{M}$; $\left[\mathrm{WO}_{3}\right]=1.0 \times 10^{-6}$ $\sim 1.0 \times 10^{-3} \mathrm{M} ;\left[\mathrm{Na}_{2} \mathrm{SO}_{4}\right]=3.3 \times 10^{-2} \mathrm{M} ; \mathrm{pH} 2$ (cationic condition: closed circle), $\mathrm{pH} 6$ (zwitterionic condition: open circle). The solid lines are fitted by Eq. (6). (g) Box approximating RhB molecule. Areas for the front (edge-on), side (flat-on), and top (end-on) faces were determined from the CPK model structure. 
Figure 5 Resolved pure monomer and dimer spectra of (a) cationic RhB, (b) zwitterionic RhB, (c) cationic Rh3B, (d) cationic Rh19, (e) zwitterionic Rh19, (f) cationic Rh6G, (g) cationic Rh110, (h) zwitterionic Rh110, and (i) cationic Rh123 in the $\mathrm{WO}_{3}$ colloid aqueous solution at $25^{\circ} \mathrm{C}$.

Figure 6 (Upper panel) Change of the absorption spectra in (a) $\mathrm{RhB} / \mathrm{WO}_{3}$, (b) $\mathrm{Rh} 19 / \mathrm{WO}_{3}$, and (c) $\mathrm{Rh} 110 / \mathrm{WO}_{3}$ aqueous system at $25^{\circ} \mathrm{C}$ as a function of $\mathrm{pH}$. Concentration conditions: [XN dye] $=1.0 \times 10^{-6} \mathrm{M} ;\left[\mathrm{WO}_{3}\right]=1.0 \times 10^{-3} \mathrm{M} ;\left[\mathrm{Na}_{2} \mathrm{SO}_{4}\right]=3.3 \times 10^{-2} \mathrm{M}$. The arrows indicate the direction of the absorbance changes with increasing $\mathrm{pH}$ value. The insets show the molar extinction coefficients at maximum wavelengths under various $\mathrm{pH}$ conditions. The lines in inset are added as a visual guide. (Lower panel) Reversible switching between $H$ - and $J$-dimerization in (d) $\mathrm{RhB} / \mathrm{WO}_{3}$, (e) $\mathrm{Rh} 19 / \mathrm{WO}_{3}$, and (f) $\mathrm{Rh} 110 / \mathrm{WO}_{3}$ aqueous system at $25^{\circ} \mathrm{C}$. Intensity changes in the molar extinction coefficients at the $H$ - (closed circle) and $J$-band (open circle) maxima under 20 cycles of the acidic $(\mathrm{pH} 2)$ and neutral $(\mathrm{pH} 6)$ treatments.

\section{Scheme titles}

Scheme 1 Molecular structure of xanthene dyes used in this study. The lowest part is a view showing a frame format of cationic and zwitterionic xanthene dyes where the rectangles and arrows represent the xanthene skeletons and the electric dipole transition moments, respectively.

Scheme 2 Schematic energy splitting for aggregates in $H$-and $J$-type arrangements based on molecular exciton coupling theory. The geometry of two chromophores (ellipses) and their electric dipoles (arrow in ellipse) are illustrated. The solid and dashed arrows from ground states to excited states represent allowed and forbidden transitions, respectively.

Scheme 3 Schematic illustrations of the possible conformations of cationic and zwitterionic XN dimer species (a) in water and (b) on the $\mathrm{WO}_{3}$ colloid surface. The rectangles and arrows represent the xanthane skeletons and the electric dipole transition moments, respectively. 
Figure 1
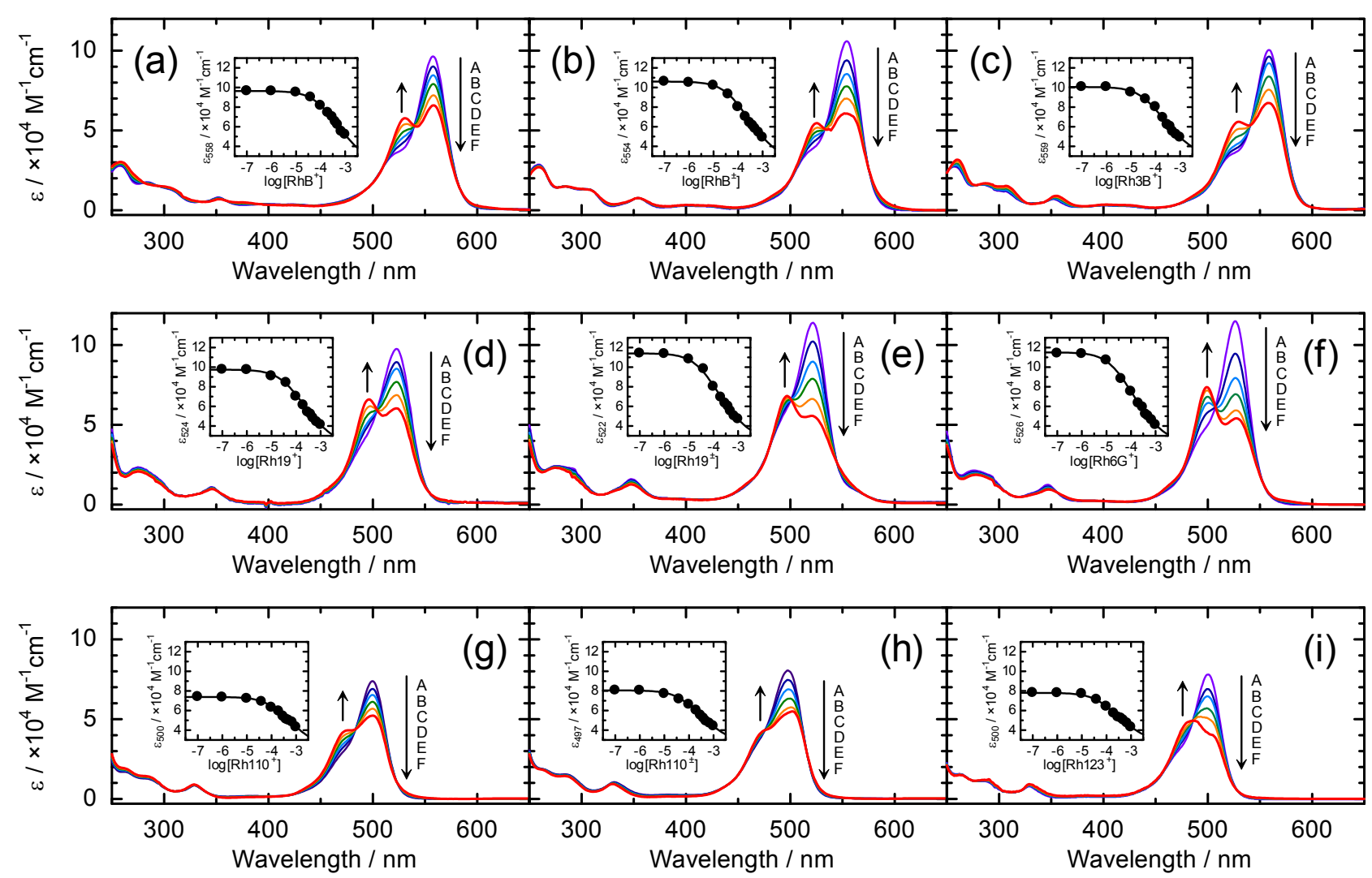
Figure 2
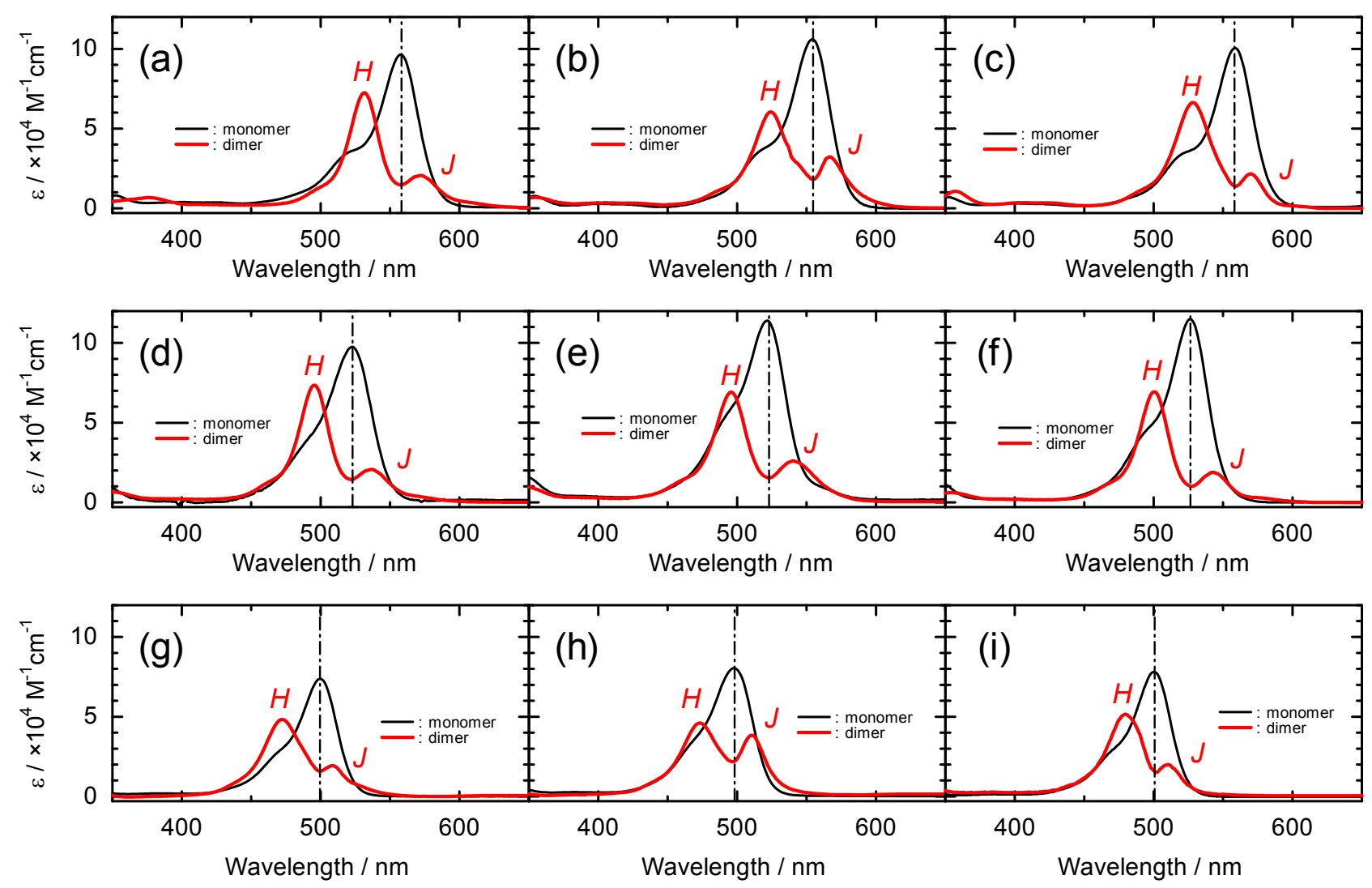
Figure 3
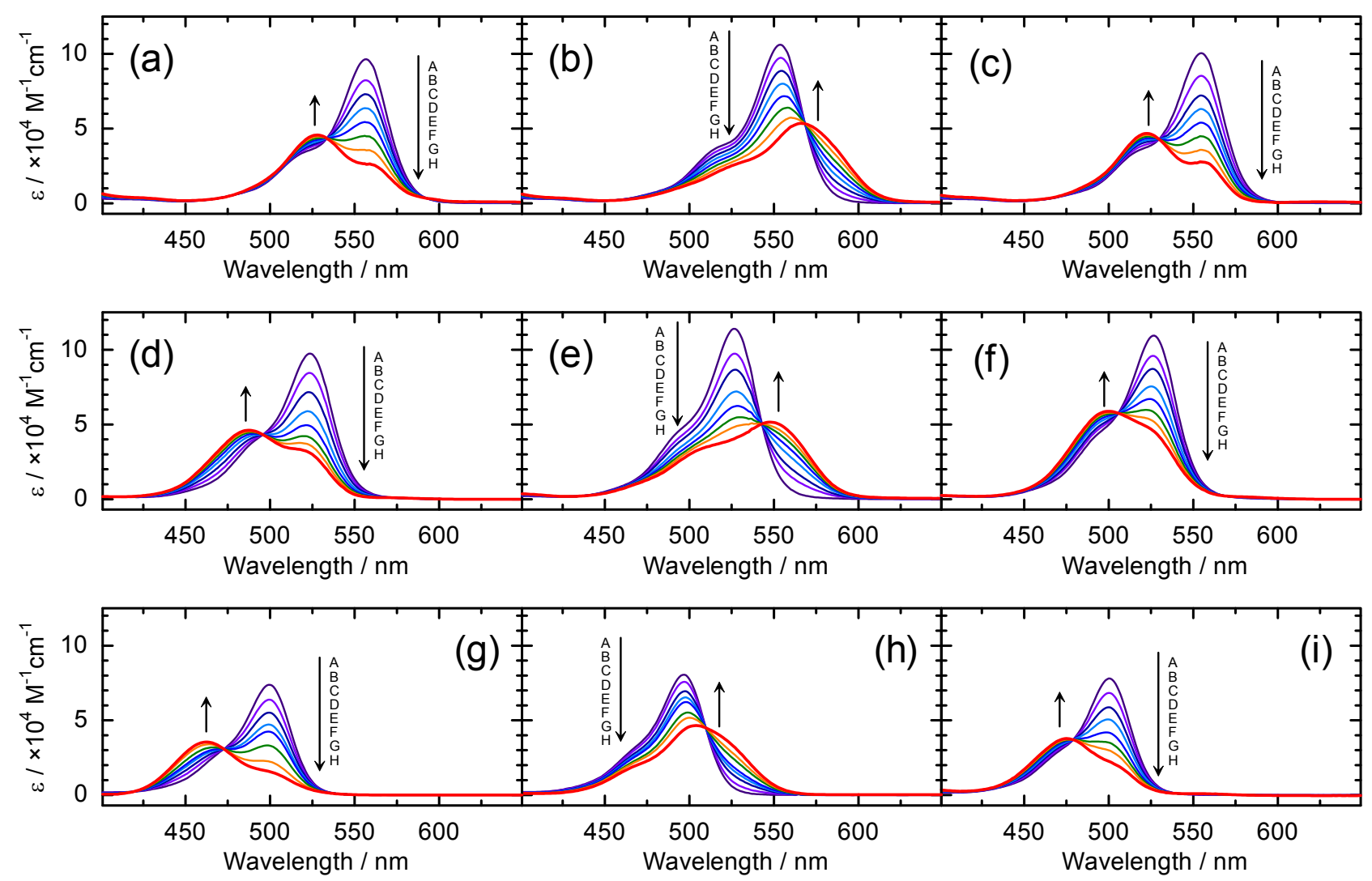
Figure 4
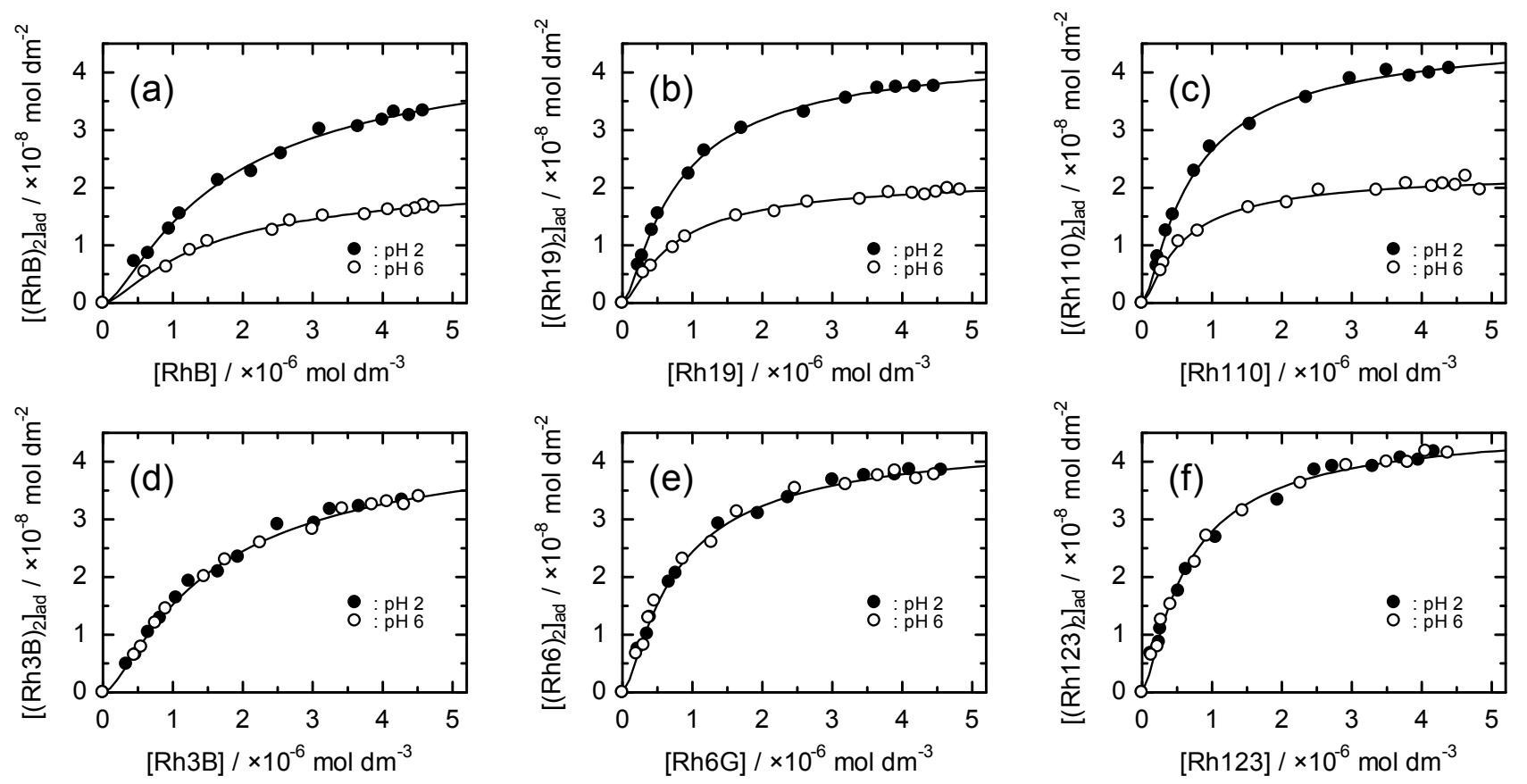

(g)

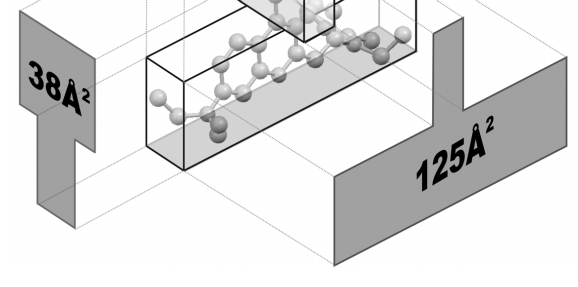


Figure 5
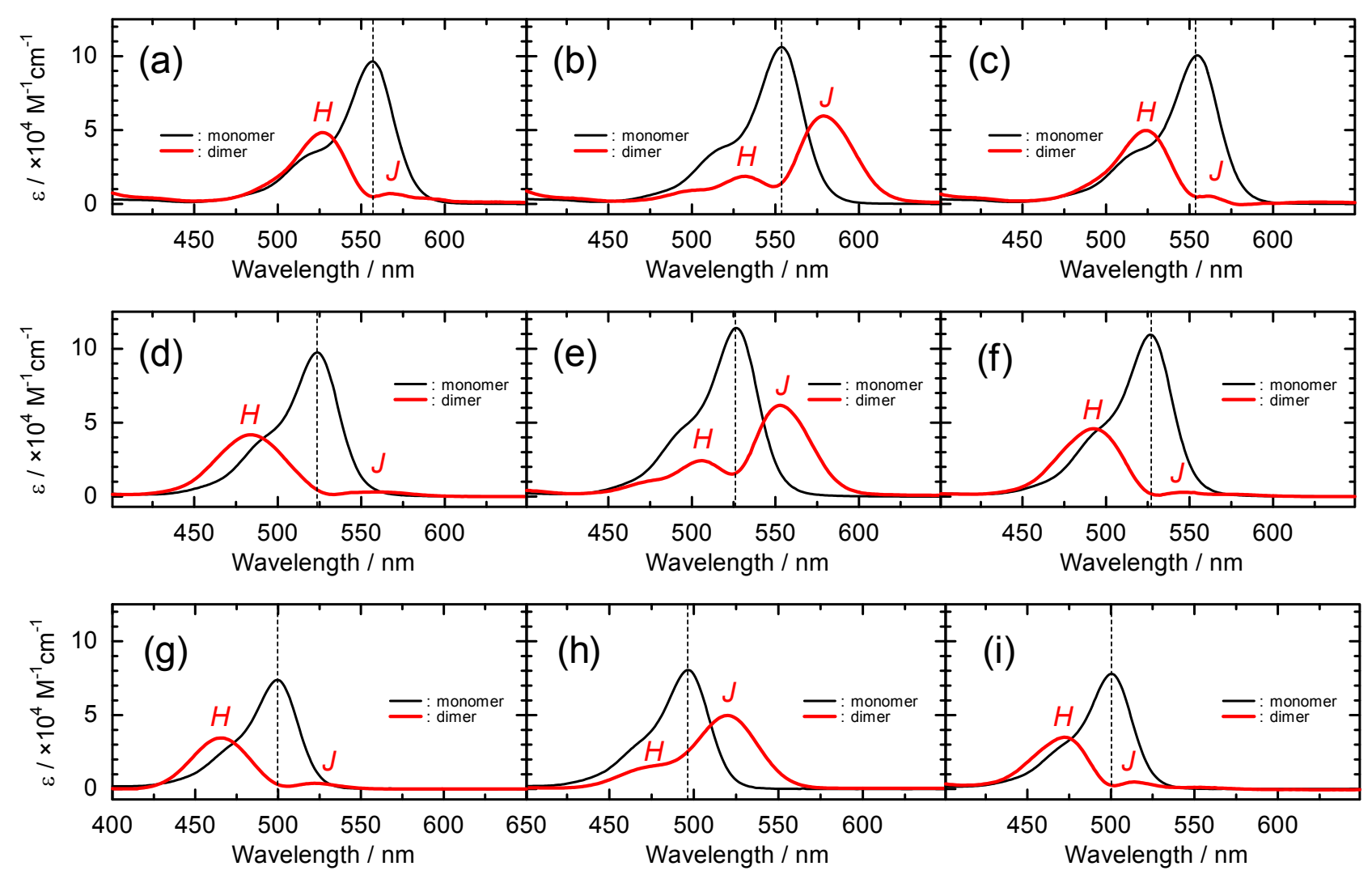
Figure 6
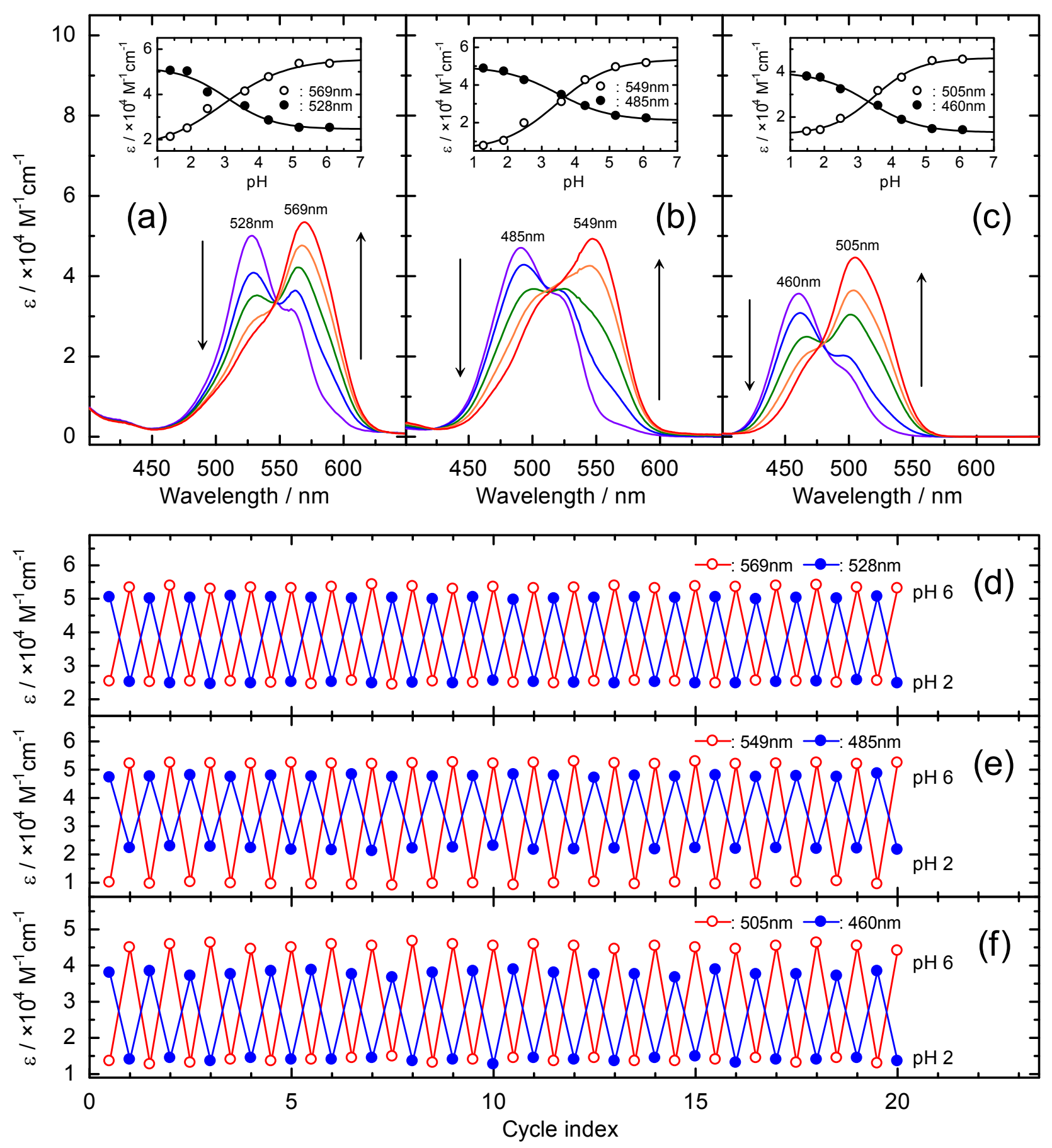
Scheme 1<smiles>CCN(CC)c1ccc2c(-c3ccccc3C(=O)O)c3ccc(=[N+](CC)CC)cc-3oc2c1</smiles>

Rhodamine B (RhB)<smiles>CCNc1cc2oc3cc(=[NH+]CC)c(C)cc-3c(-c3ccccc3C(=O)O)c2cc1C</smiles>

Rhodamine 19

(Rh19)<smiles></smiles>

Rhodamine 110

(Rh110)<smiles></smiles>

Rhodamine 3B

(Rh3B)

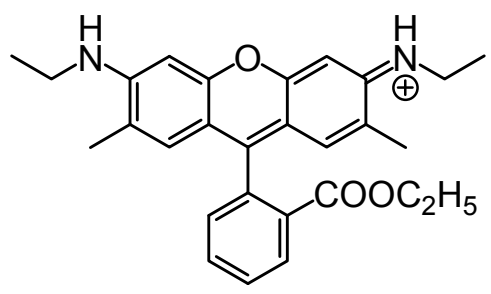

Rhodamine 6G (Rh6G)<smiles></smiles>

Rhodamine 123

(Rh123)

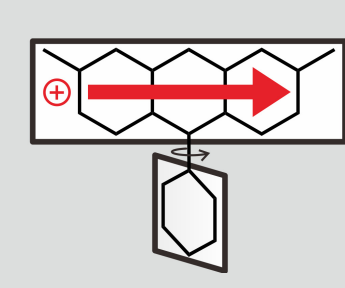

cationic

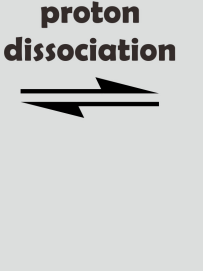

zwitterionic 
Scheme 2

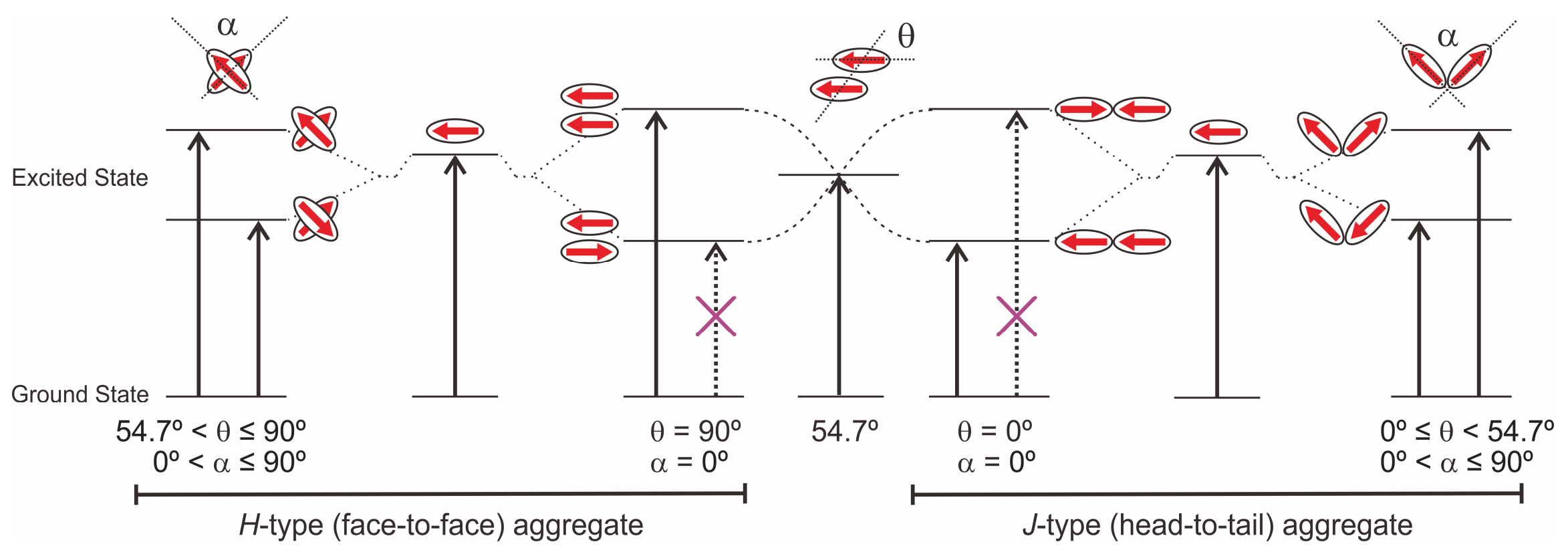


Scheme 3

(a)

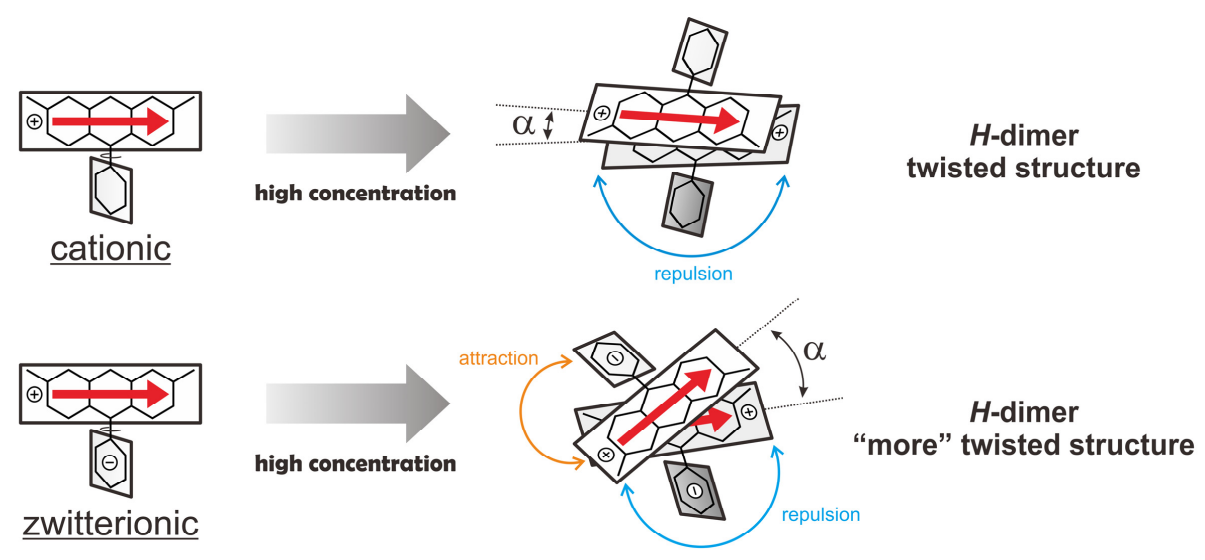

(b)
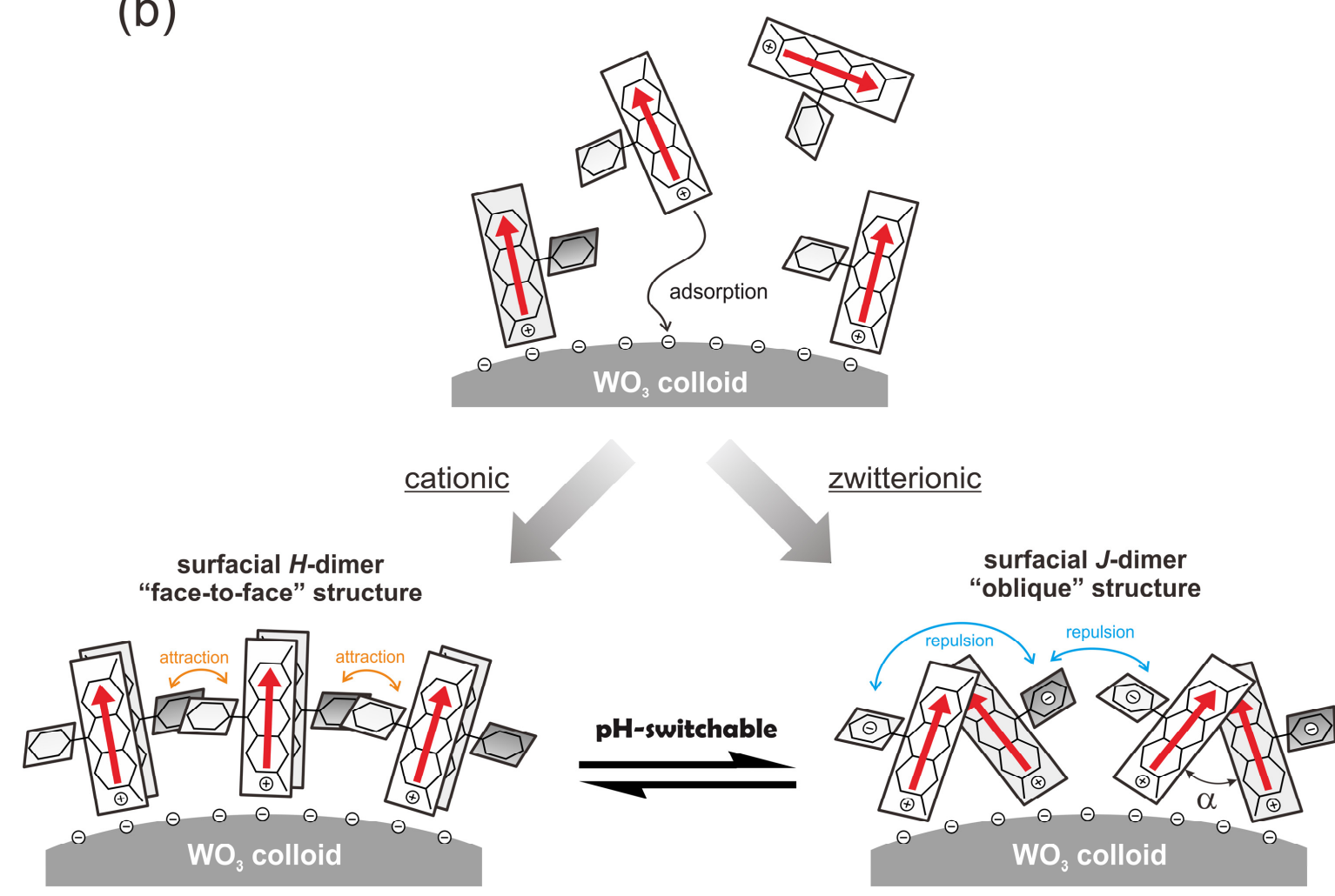

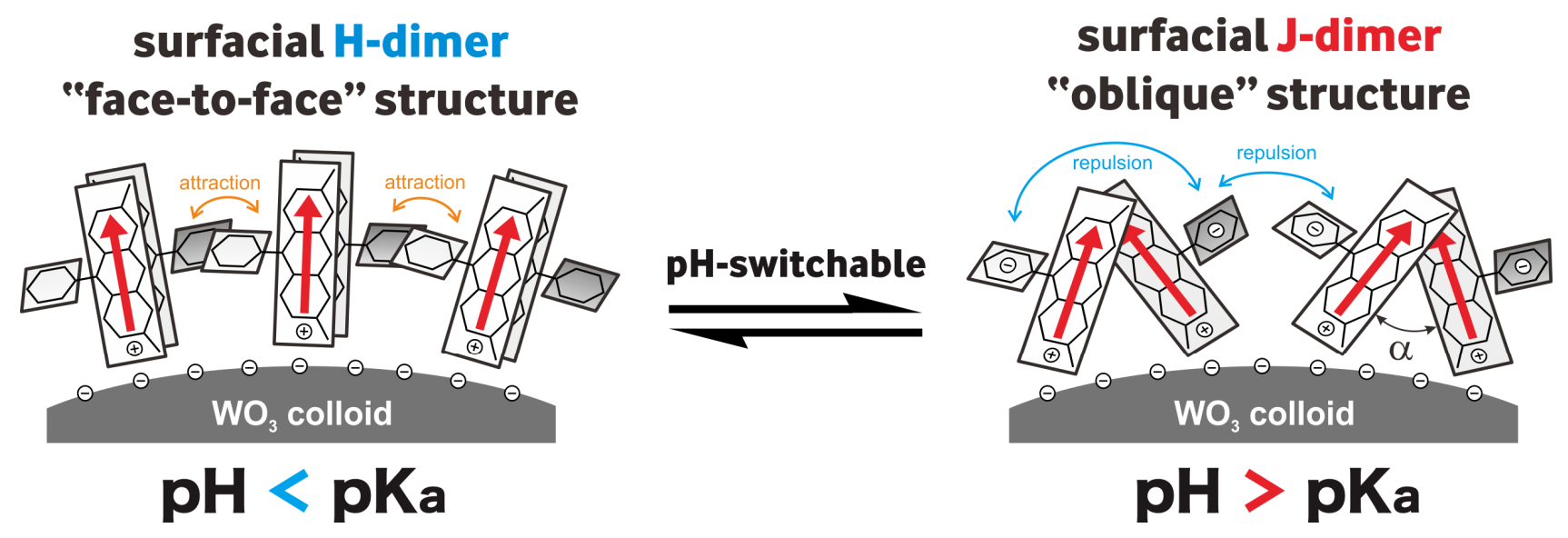